\title{
KEY FACTORS THAT INFLUENCE THE PERFORMANCE PROPERTIES OFARP/MCU SALTSTONE MIXES
}

\author{
J. R. Harbour, T. B. Edwards and V. J. Williams \\ Savannah River National Laboratory
}

September 2009

Savannah River National Laboratory

Savannah River Nuclear Solutions

Aiken. SC 29808

Prepared for the U.S. Department of Energy Under

Contract Number DE-AC09-08SR22470

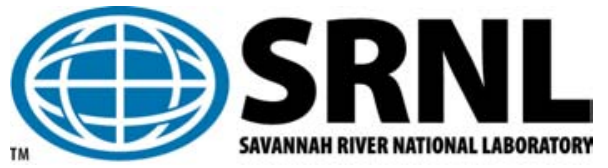




\section{DISCLAIMER}

This work was prepared under an agreement with and funded by the U.S. Government. Neither the U.S. Government or its employees, nor any of its contractors, subcontractors or their employees, makes any express or implied: 1. warranty or assumes any legal liability for the accuracy, completeness, or for the use or results of such use of any information, product, or process disclosed; or 2. representation that such use or results of such use would not infringe privately owned rights; or 3. endorsement or recommendation of any specifically identified commercial product, process, or service. Any views and opinions of authors expressed in this work do not necessarily state or reflect those of the United States Government, or its contractors, or subcontractors.

\section{Printed in the United States of America}

Prepared For U.S. Department of Energy 
Key Words: Curing Temperature Porosity

Young's Modulus

Retention: Permanent

\title{
KEY FACTORS THAT INFLUENCE THE PERFORMANCE PROPERTIES OFARP/MCU SALTSTONE MIXES
}

\author{
J. R. Harbour, T. B. Edwards and V. J. Williams \\ Savannah River National Laboratory
}

September 2009

Savannah River National Laboratory

Savannah River Nuclear Solutions

Aiken, SC 29808

Prepared for the U.S. Department of Energy Under

Contract Number DE-AC09-08SR22470

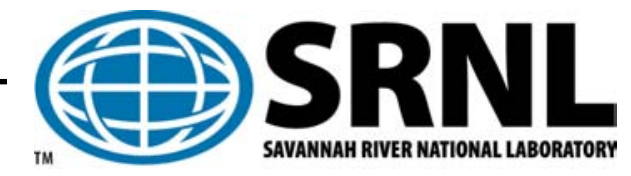




\section{REVIEWS AND APPROVALS}

\section{AUTHORS:}

J. R. Harbour, SRNL, Engineering Process Development

Date

T. B. Edwards, SRNL, Applied Comp Eng \& Statistics

Date

V. J. Williams, SRNL, Engineering Process Development

Date

TECHNICAL REVIEWERS:

M. M. Reigel, SRNL, Engineering Process Development

Date

\section{APPROVERS}

A. B. Barnes, SRNL, Manager, Engineering Process Development

Date

S. L. Marra, SRNL, Manager, E\&CPT Research Programs

Date

J. E. Occhipinti, Manager, Waste Solidification Engineering

Date 


\section{EXECUTIVE SUMMARY}

This report details the results from Task 3 of the Saltstone Variability Study for FY09 which was performed to identify and quantify, when possible, those factors that drive the performance properties of the projected Actinide Removal Process/ Modulated Caustic Side Solvent (ARP/MCU) Batches. A baseline ARP/MCU mix (at $0.60 \mathrm{w} / \mathrm{cm}$ ratio) was established and consisted of the normal premix composition and a salt solution that was an average of the projected compositions of the last three ARP/MCU batches developed by T. A. Le. The strategy for this task introduced significant variation in (1) $\mathrm{wt} \% \mathrm{slag}, \mathrm{w} / \mathrm{cm}$ ratio, and $\mathrm{wt} \%$ portland cement about the baseline mix and (2) the temperature of curing in order to better assess the dependence of the performance properties on these factors.

The baseline salt solution contained the projected value of $0.22 \mathrm{M}$ aluminate which was held constant for all mixes except one. The exception was a mix batched with a salt solution containing $0.05 \mathrm{M}$ aluminate (previous baseline) but equivalent to the baseline salt solution in all other constituents. The relatively high $0.22 \mathrm{M}$ aluminate concentration (compared with the 0.05 $\mathrm{M}$ aluminate mix) in the projected ARP/MCU batches more than doubled Young's modulus from 4.2 to $8.8 \mathrm{GPa}$. Therefore, the higher concentration of aluminate in the new baseline salt solution significantly improved performance for mixes cured at $22{ }^{\circ} \mathrm{C}$.

For samples cured at $22{ }^{\circ} \mathrm{C}$, a decrease in the w/cm ratio from 0.65 to 0.50 in these mixes increased Young's modulus and decreased total porosity. An increase in the wt \% slag from 45 to $60 \mathrm{wt} \%$ also increased Young's modulus and reduced total porosity. This is consistent with previous findings and leads to the conclusion that $\mathrm{w} / \mathrm{cm}$ ratio and slag content are important factors that drive the performance properties.

For samples cured at $22{ }^{\circ} \mathrm{C}$, an increase in the cement content in the premix from 10 to $30 \mathrm{wt} \%$ decreased $\mathrm{E}$ from 8.8 to $7.2 \mathrm{GPa}$. This effect is opposite to that of increased slag concentration in the premix. However, this result is consistent with literature findings that show slag produces mixes that have lower permeabilities and porosities. For cement content of 15 or $30 \mathrm{wt} \%$ in the premix, a decrease in $\mathrm{w} / \mathrm{cm}$ ratio increased Young's modulus and decreased total porosity.

Linear, empirical models were developed and are presented in this report for Young's modulus, total porosity and heat of hydration using data from the $22{ }^{\circ} \mathrm{C}$ cured samples. The $\mathrm{R}^{2}$ values for these three models ranged from $92 \%$ to $99 \%$ and identified the statistically significant factors that influenced these properties for this study.

An increase in the curing temperature in general reduced Young's modulus and increased total porosity. For example the baseline mix cured at $54{ }^{\circ} \mathrm{C}$ had a Young's modulus value roughly half the value of the sample cured at $22{ }^{\circ} \mathrm{C}$. This reduction in performance properties for samples cured at higher temperatures is mitigated by an increase in the cement content of the premix. For a mix containing $30 \mathrm{wt} \%$ cement (at the expense of fly ash), the value of Young's modulus was essentially equivalent for samples cured at $60{ }^{\circ} \mathrm{C}$ and $22^{\circ} \mathrm{C}$.

For the mixes containing variable slag concentration, the processing properties were generally acceptable except for those mixes at the lowest $\mathrm{w} / \mathrm{cm}$ ratios. The measured gel times for these 
mixes were 10 minutes and the viscosities and yield strengths were higher than normal. Similar results were found for mixes containing high levels of cement. These mixes exhibited short gel times and increased viscosities and yield strengths.

Samples from these tests were dried at $40{ }^{\circ} \mathrm{C}$ until they had lost $\sim 20 \mathrm{wt} \%$ due to water evaporation. When these dried samples were broken apart, the smaller pieces that resulted had many surfaces indicating cleavage along internal cracks. This behavior was observed with all samples containing $0.22 \mathrm{M}$ aluminate but not for the mix containing $0.05 \mathrm{M}$ aluminate. In the $0.05 \mathrm{M}$ aluminate case, there was a clean break in the cylindrical sample with the large pieces having smooth surfaces.

When partially dried samples (mass loss $<10 \mathrm{wt} \%$ ) were broken apart, the cross sectional area consisted of distinct regions. The outer region was highly fractured whereas the inner region was blue in color, saturated and intact. A mechanism of shrinkage and subsequent cracking accounts for these observations. Evidently, the samples dry from the outside first which leads to shrinkage and then cracking of the grout. This dried and cracked region is highly permeable such that water from the inner regions escapes from the grout by passing through this porous outer region as drying continues. The kinetics of this process are such that a very sharp demarcation boundary exists between the two phases. Photographs of the dried and cracked grouts are provided in the report. 


\section{TABLE OF CONTENTS}

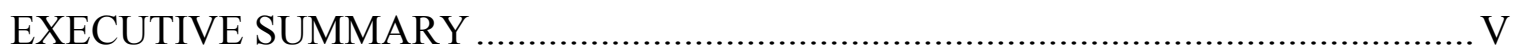

LIST OF FIGURES ……………………………….................................... VII

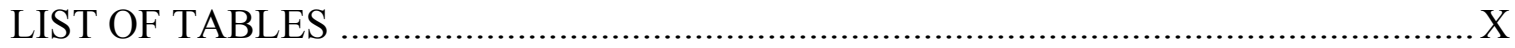

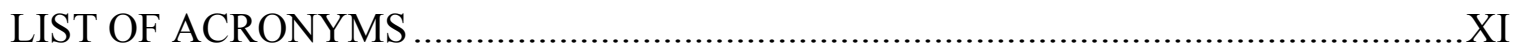

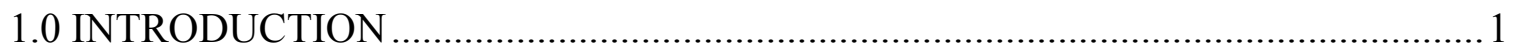

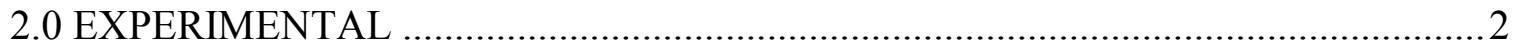

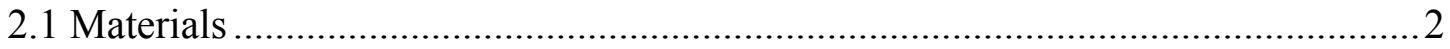

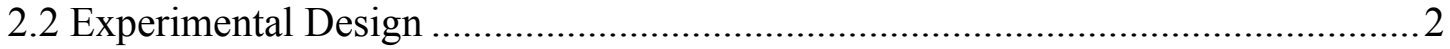

2.3 Measurement of Properties...............................................................................

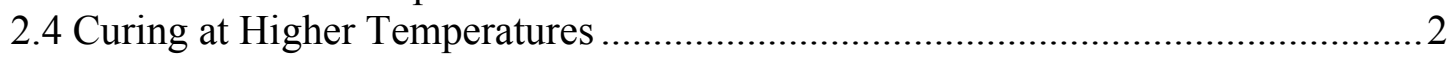

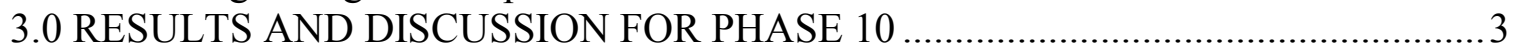

3.1 Impact of Aluminate ..................................................................................... 3

3.2 Phase 10 - Young's Modulus as a Function of w/cm Ratio and Wt \% BFS...........5

3.3 Young's Modulus at Different Time/Temperature Curing Profiles ......................... 7

3.4 Porosities as a Function of Curing Temperature and Time .....................................

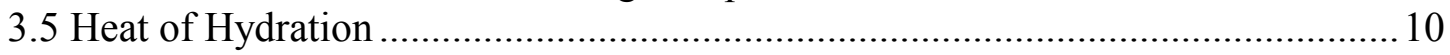

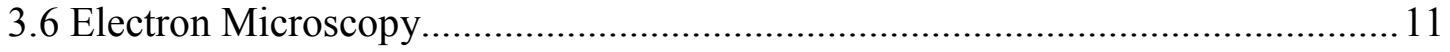

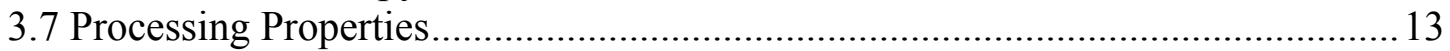

3.8 Drying Shrinkage and Cracking ....................................................................... 13

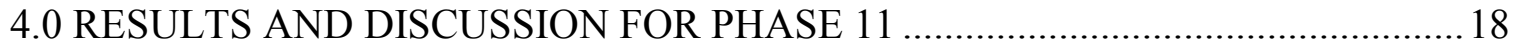

4.1 Impact of Increased Cement Content in the Mix.................................................... 18

4.2 Phase $11-\mathrm{E}$ as a Function of $\mathrm{w} / \mathrm{cm}$ Ratio and Wt \% Cement............................... 19

4.3 Young's Modulus at Different Time/Temperature Curing Profiles ........................20

4.4 Porosities as a Function of Curing Temperature and Time ....................................21

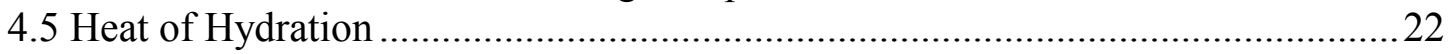

4.6 Processing Properties for Phase 11 Mixes..........................................................22

4.7 Drying Shrinkage and Cracking .........................................................................2

5.0 CORRELATION OF POROSITY AND YOUNG'S MODULUS ............................25

6.0 PREDICTIVE MODELING FOR E, $\Phi$ AND HEAT OF HYDRATION ...................27

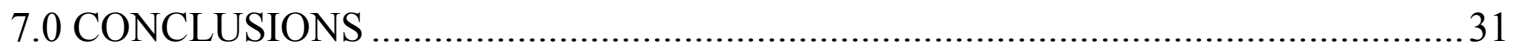

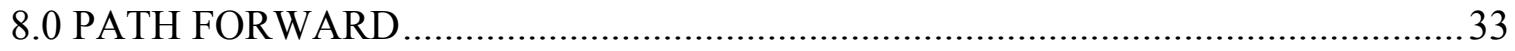

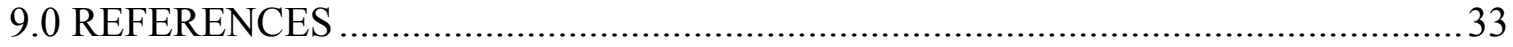




\section{LIST OF FIGURES}

Figure 3-1 Comparison of the heat of hydration for GVS107 and GVS110................4 Figure 3-2 Young's modulus (E) values for eight ARP/MCU mixes as a function of w/cm ratio

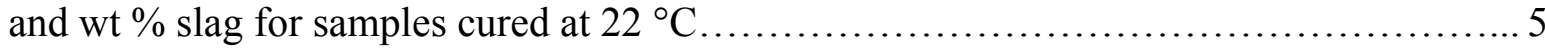

Figure 3-3 Time dependence of $\mathrm{E}$ for nine ARP/MCU mixes as a function of $\mathrm{w} / \mathrm{cm}$ ratio and $\mathrm{wt}$

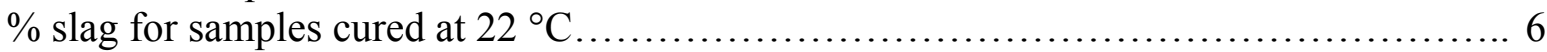

Figure 3-4 Young's modulus values for ARP/MCU mixes containing 45 or $60 \mathrm{wt} \%$ slag after curing at the indicated temperatures for 28 days. The data points for the cyan colored x's were obtained on the samples removed from the $54{ }^{\circ} \mathrm{C}$ oven at 1 week and measured at 28

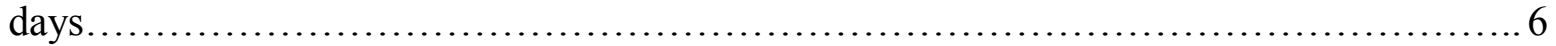

Figure 3-5 Time dependence of $\mathrm{E}$ for samples cured at either $40{ }^{\circ} \mathrm{C}$ or $54{ }^{\circ} \mathrm{C}$ for 28 days and then removed, sealed and stored at ambient temperature................................. 7

Figure 3-6 Time dependence of E in GPa for GVS109 (45 wt \% slag) at indicated time and

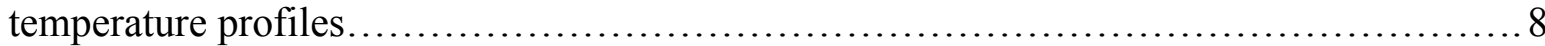

Figure 3-7 Time dependence of E in GPa for GVS109 (45 wt \% slag) at indicated time and

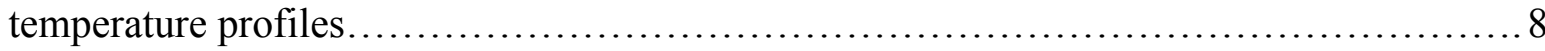

Figure 3-8 Time dependence of E in GPa for GVS1 $13(0.55 \mathrm{w} / \mathrm{cm}$ ratio and $60 \mathrm{wt} \% \mathrm{slag})$ at indicated time and temperature profiles......................................... 9

Figure 3-9 Total porosity for mixes batched with either 45 or $60 \mathrm{wt} \%$ slag as a function of w/cm

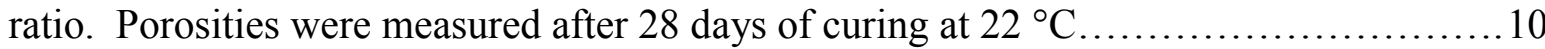

Figure 3-10 Total porosity as a function of $\mathrm{w} / \mathrm{cm}$ ratio for 3 cure temperatures................. 10 Figure 3-11 BSE micrographs of polished samples of GVS1 1 cured at $22{ }^{\circ} \mathrm{C}$ and $54{ }^{\circ} \mathrm{C} \ldots \ldots . .12$ Figure 3-12 Wt \% loss of GVS samples numbered 107 through 115 as a function of time in the

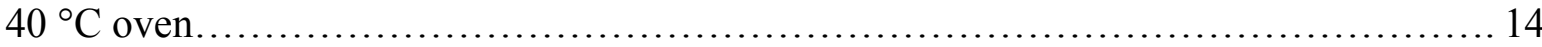

Figure 3-13 GVS107 after drying (image on the left) and then after being broken apart........ 15 Figure 3-14 Cast cylinder of GVS111 after rehydration and cracking....................... 15 Figure 3-15 Cast cylinder of GVS108 after rehydration and broken apart using a hammer...... 16 Figure 3-16 A partially dried cured sample (2 inch diameter) from premix and 3.0 $\mathrm{M} \mathrm{NaOH}$ at $0.60 \mathrm{w} / \mathrm{cm}$ ratio and cured at $22^{\circ} \mathrm{C}$. This sample was easily broken by hand............ 17

Figure 4-1 E vs. wt \% cement in baseline ARP/MCU mix for samples cured at $22{ }^{\circ} \mathrm{C} \ldots \ldots . . . .19$ Figure 4-2 Time dependence of $\mathrm{E}$ at $22{ }^{\circ} \mathrm{C}$ curing temperature for the five mixes of Phase 11 plus

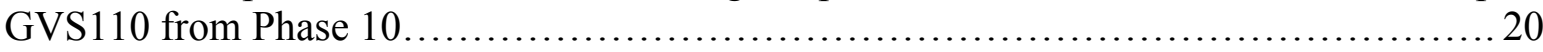

Figure 4-3 E as a function of curing time for the profiles given in the legend for GVS118.....21 Figure 4-4 Mass loss in wt \% for the $2 \times 4$ inch cast samples of GVS116 through GVS120..... 24 Figure 4-5 A comparison of mass loss in wt \% for drying at $40{ }^{\circ} \mathrm{C}$ vs. $105^{\circ} \mathrm{C}$ for the $2 \times 4$ inch cast samples of GVS1 16 through GVS120...................................24

Figure 4-6 Photographs of GVS120 after drying and rehydration (left side) and breakage (right

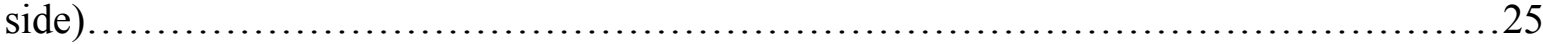

Figure 5-1 Correlation of $\mathrm{E}$ and $\Phi$ for Phases 10 and 11 mixes cured at $22{ }^{\circ} \mathrm{C}$. The purple circles are Phase 11 mixes and the gold squares are Phase 10 mixes........................ 26

Figure 5-2 Bivariate fit of Young's modulus to total porosity for mixes of Phases 10 and 11 measured at all three curing temperatures. The purple circles are Phase 11 mixes and the

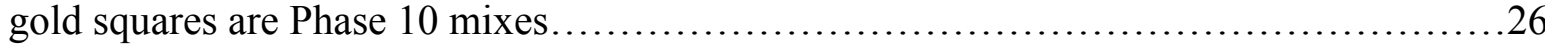


Figure 6-1 Actual versus predicted values of Young's modulus for samples of Phases 10 and 11

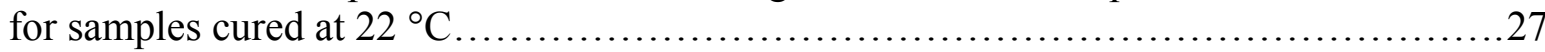

Figure 6-2 Actual vs. predicted values of total porosity for samples of Phases 10 and 11 for

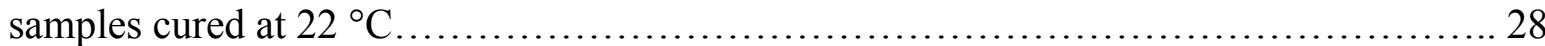

Figure 6-3 Actual vs. predicted values of heat of hydration for samples of Phases 10 and 11 for samples cured $25^{\circ} \mathrm{C}$ only................................................. 28

Figure 6-4 Actual versus predicted values of Young's modulus for samples of Phases 10 and 11 for samples cured at all three temperatures........................................29

Figure 6-5 Actual vs. predicted values of total porosity for samples of Phases 10 and 11 for samples cured at all three temperatures............................................29 


\section{LIST OF TABLES}

Table 2-1 Saltstone Cementitious Materials and Current Premix Blend. ....................................2

Table 3-1 Experimental Design for Phase 10..................................................................... 3

Table 3-2 Fresh and Cured Grout Properties for GVS107 and GVS110 ................................4

Table 3-3 Heat of Hydration and Peak Time for Heat Generation for Phase 10 Mixes...............11

Table 3-4 Processing Properties for Phase 10 Mixes. ......................................................13

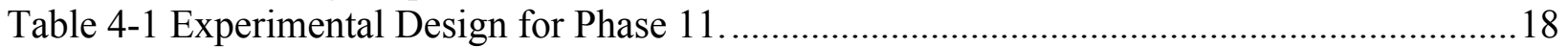

Table 4-2 Fresh and Cured Grout Properties for GVS110 and GVS1 18 ................................18

Table 4-3 Young's Modulus Values for the Phase 11 Mixes..................................................19

Table 4-4 Total Porosity Values for the Phase 11 Mixes.......................................................22

Table 4-5 Heat of Hydration and Peak Time for Heat Generation for Phase 11 Mixes...............22

Table 4-6 Processing Properties for Phase 11 Mixes..........................................................23 


\section{LIST OF ACRONYMS}

\begin{tabular}{|l|l|}
\hline ACTL & Aiken County Technology Laboratory \\
\hline ARP & Actinide Removal Process \\
\hline BSE & Back Scattered Electrons \\
\hline CBO & Carbon Burn-Out \\
\hline CSH & Calcium Silicate Hydrate \\
\hline E & Young's Modulus \\
\hline FA & Class F Fly Ash \\
\hline BFS & Blast Furnace Slag \\
\hline DSS & Decontaminated Salt Solution \\
\hline GPa & Giga Pascals \\
\hline GVS & Grout Variability Study \\
\hline ISDP & Interim Salt Disposition Processing \\
\hline M & Molarity \\
\hline MCU & Modular Caustic Side Solvent Extraction \\
\hline OPC & Ordinary Portland Cement \\
\hline$\Phi$ & Total Porosity \\
\hline PA & Performance Assessment \\
\hline PC & Portland Cement \\
\hline SDF & Saltstone Disposal Facility \\
\hline SEM & Scanning Electron Microscopy \\
\hline SPF & Saltstone Production Facility \\
\hline SRNL & Savannah River National Laboratory \\
\hline SRNS & Savannah River Nuclear Solutions \\
\hline SRS & Savannah River Site \\
\hline SWPF & Salt Waste Processing Facility \\
\hline T & Temperature \\
\hline TR & Trial Run \\
\hline w/cm & Water to Cementitious Material Ratio \\
\hline Wt & Weight \\
\hline
\end{tabular}




\subsection{INTRODUCTION}

At the Saltstone Production Facility (SPF), decontaminated salt solution (DSS) is combined with premix (a cementitious mixture of portland cement (PC), blast furnace slag (BFS) and Class F fly ash (FA)) in a Readco mixer to produce fresh (uncured) Saltstone. After transfer to the Saltstone Disposal Facility (SDF) the hydration reactions initiated during the contact of the premix and salt solution continue during the curing period to produce the hardened waste form product. The amount of heat generated from hydration and the resultant temperature increase in the vaults depend on the composition of the decontaminated salt solution being dispositioned as well as the grout formulation (mix design).

This report details the results from Task 3 of the Saltstone Variability Study for FY09 [1] which was performed to identify, and quantify when possible, those factors that drive the performance properties of the projected ARP/MCU Batches. A baseline ARP/MCU mix (at 0.60 water to cementitious materials $(\mathrm{w} / \mathrm{cm})$ ratio) was established and consisted of the normal premix composition and a salt solution that was an average of the projected compositions of the last three ARP/MCU batches developed by T. A. Le [2]. This task introduced significant variation in (1) wt \% slag, w/cm ratio, and wt \% portland cement about the baseline mix and (2) the temperature of curing in order to better assess the dependence of the performance properties on these factors.

Two separate campaigns, designated Phase 10 and Phase 11, were carried out under Task 3. Experimental designs and statistical analyses were used to search for correlation among properties and to develop linear models to predict property values based on factors such as w/cm ratio, slag concentration, and portland cement concentration. It turns out that the projected salt compositions contained relatively high amounts of aluminate $(0.22 \mathrm{M})$ even though no aluminate was introduced due to caustic aluminate removal from High Level Waste. Previous studies revealed that increased levels of aluminate in the feed cause a significant increase in the heat generation [3]. For Phase 10, a mix with $0.05 \mathrm{M}$ aluminate was used as a comparison point for the mixes at $0.22 \mathrm{M}$ aluminate.

The temperature of curing in Task 3 ranged from $22^{\circ} \mathrm{C}$ to $75{ }^{\circ} \mathrm{C}$. Recent results [4] demonstrated that it is not only the temperature of curing which is important but also the time/temperature sequence of curing. Therefore, this report also focuses on the impact of the sequencing of time and curing temperature on Saltstone properties. 


\subsection{EXPERIMENTAL}

\subsection{Materials}

The cementitious materials were obtained from Saltstone in five gallon containers and are listed in Table 2-1. These materials were specified in a contract for Saltstone cementitious materials and arrived with the delivery of the cementitious materials to Saltstone. The materials were transferred to smaller high-density polyethylene bottles at Aiken County Technology Laboratory (ACTL) and the bottles were tightly sealed. Maintaining these materials in a tightly sealed container limits the exposure of the materials to humid air and hydration prior to use. Table 2-1 also contains the wt $\%$ contribution of each material used to make the nominal premix. The fly ash used in this study was a material that had been thermally treated by the vendor to remove most of the carbon and ammonia (carbon burnout or CBO fly ash).

Table 2-1 Saltstone Cementitious Materials and Current Premix Blend.

\begin{tabular}{|c|c|c|c|}
\hline Material & Category & Vendor & Premix Blend (wt\%) \\
\hline Portland cement (OPC) & Type II & Holcim & 10 \\
\hline Blast Furnace slag (GGBFS) & Grade I or II & Holcim & 45 \\
\hline Fly ash (FA) & Class F & SEFA & 45 \\
\hline
\end{tabular}

\subsection{Experimental Design}

The mixes prepared for this study were included in either Phase 10 or 11 of the Saltstone Variability study. The designs for both phases are presented with the results of these studies in Sections 3 and 4.

\subsection{Measurement of Properties}

The measurements of heat of hydration [4], dynamic Young's modulus [5], porosity [6], and processing properties such as set time [7] were performed by the methods used previously.

\subsection{Curing at Higher Temperatures}

Samples were cured at ambient (also referred to as room temperature in this report) conditions in the laboratory (typically $22^{\circ} \mathrm{C}$ ), at $40^{\circ} \mathrm{C}$ or at higher temperatures $\left(54{ }^{\circ} \mathrm{C}\right.$ and $75{ }^{\circ} \mathrm{C}$ for Phase 10 or $60^{\circ} \mathrm{C}$ for Phase 11). In all cases the grout was poured into the cylinders, capped and securely taped. Measurement of the mass of the samples with container, lid and tape were made prior to and after curing to measure any mass loss during curing. At ambient temperature and at $40{ }^{\circ} \mathrm{C}$ curing conditions, essentially no change in the mass after curing was noted. For the $54{ }^{\circ} \mathrm{C}$ and the $60{ }^{\circ} \mathrm{C}$ curing conditions, a mass loss on the order of 1 to 2 grams was observed. For example, the Young's modulus cylinder and sample have a starting mass of $\sim 1100$ grams. Therefore, a loss of 1 gram corresponds to only $\sim 0.1 \mathrm{wt} \%$ of the total mass of the sample. 
The ovens have temperature gradients within the interior of the ovens. Therefore, the range of temperatures for a given sample may be as great as $\pm 5^{\circ} \mathrm{C}$ about a set temperature.

Thermocouples and thermometers were used to measure the actual temperatures within the oven.

\subsection{RESULTS AND DISCUSSION FOR PHASE 10}

The results presented in this report were generated as part of Task 3 of the Saltstone Variability Study for FY09 and focus on the dependence of performance properties on factors such as w/cm ratio, wt \% BFS, wt \% PC and temperature of curing. Simulants used in this task were based on projections of the ARP/MCU batches provided by T. A. Le [2]. An experimental design was developed that used the baseline composition with variation introduced in the $\mathrm{w} / \mathrm{cm}$ ratio and in the amount of BFS. An additional mix was added to the design that contained $0.05 \mathrm{M}$ aluminate rather than the $0.22 \mathrm{M}$ aluminate projected by Le to assess the impact of aluminate on the properties. Task 3 was comprised of Phases 10 and 11 of the Variability Study. Section 3 of this report focuses on Phase 10 of Task 3 with an experimental design as provided in Table 3-1. Phase 11 results are presented in Section 4 of this report.

Table 3-1 Experimental Design for Phase 10.

\begin{tabular}{|c|c|c|c|c|c|c|c|c|c|c|c|}
\hline \multicolumn{10}{|c|}{ MCU Grout Variability Study Phase 10} & \multirow[b]{2}{*}{ Phosphate } & \multirow[b]{2}{*}{ Aluminate } \\
\hline Run Number & Temp & Water/Premix & Water/Premix & OPC & FA & Slag & Added OH & Free $\mathrm{OH}$ & Nitrate plus Nitrite & & \\
\hline Run Order & $\mathrm{OC}$ & Nominal & As Batched & Wt \% & Wt \% & Wt $\%$ & $M$ & $M$ & $M$ & $M$ & $\mathrm{M}$ \\
\hline GVS107 & 22 & 0.60 & 0.605 & 10 & 45 & 45 & 2.00 & 1.80 & 2.91 & 0.012 & 0.05 \\
\hline GVS108 & 22 & 0.50 & 0.493 & 10 & 45 & 45 & 2.68 & 1.80 & 2.91 & 0.012 & 0.22 \\
\hline GVS109 & 22 & 0.55 & 0.542 & 10 & 45 & 45 & 2.68 & 1.80 & 2.91 & 0.012 & 0.22 \\
\hline GVS110 & 22 & 0.60 & 0.591 & 10 & 45 & 45 & 2.68 & 1.80 & 2.91 & 0.012 & 0.22 \\
\hline GVS111 & 22 & 0.65 & 0.640 & 10 & 45 & 45 & 2.68 & 1.80 & 2.91 & 0.012 & 0.22 \\
\hline GVS112 & 22 & 0.50 & 0.493 & 10 & 30 & 60 & 2.68 & 1.80 & 2.91 & 0.012 & 0.22 \\
\hline GVS113 & 22 & 0.55 & 0.542 & 10 & 30 & 60 & 2.68 & 1.80 & 2.91 & 0.012 & 0.22 \\
\hline GVS114 & 22 & 0.60 & 0.591 & 10 & 30 & 60 & 2.68 & 1.80 & 2.91 & 0.012 & 0.22 \\
\hline GVS115 & 22 & 0.65 & 0.640 & 10 & 30 & 60 & 2.68 & 1.80 & 2.91 & 0.012 & 0.22 \\
\hline
\end{tabular}

\subsection{Impact of Aluminate}

A comparison on the impact of aluminate on the ARP/MCU mix properties was made using two mixes that were identical except for the aluminate concentration $(0.05 \mathrm{M}$ for GVS107 vs. $0.22 \mathrm{M}$ for GVS110). Thuy Le projected that the remaining three batches of ARP/MCU will have aluminate concentrations of $0.22 \mathrm{M}$. Figure 3-1 shows the comparison of the heat of hydration as a function of time for these two mixes at $25{ }^{\circ} \mathrm{C}$. The higher aluminate level in GVS110 leads to an induction period followed by an increased heat of hydration consistent with previous results. GVS107 was the only mix batched at the $0.05 \mathrm{M}$ aluminate level for Phase 10 . 


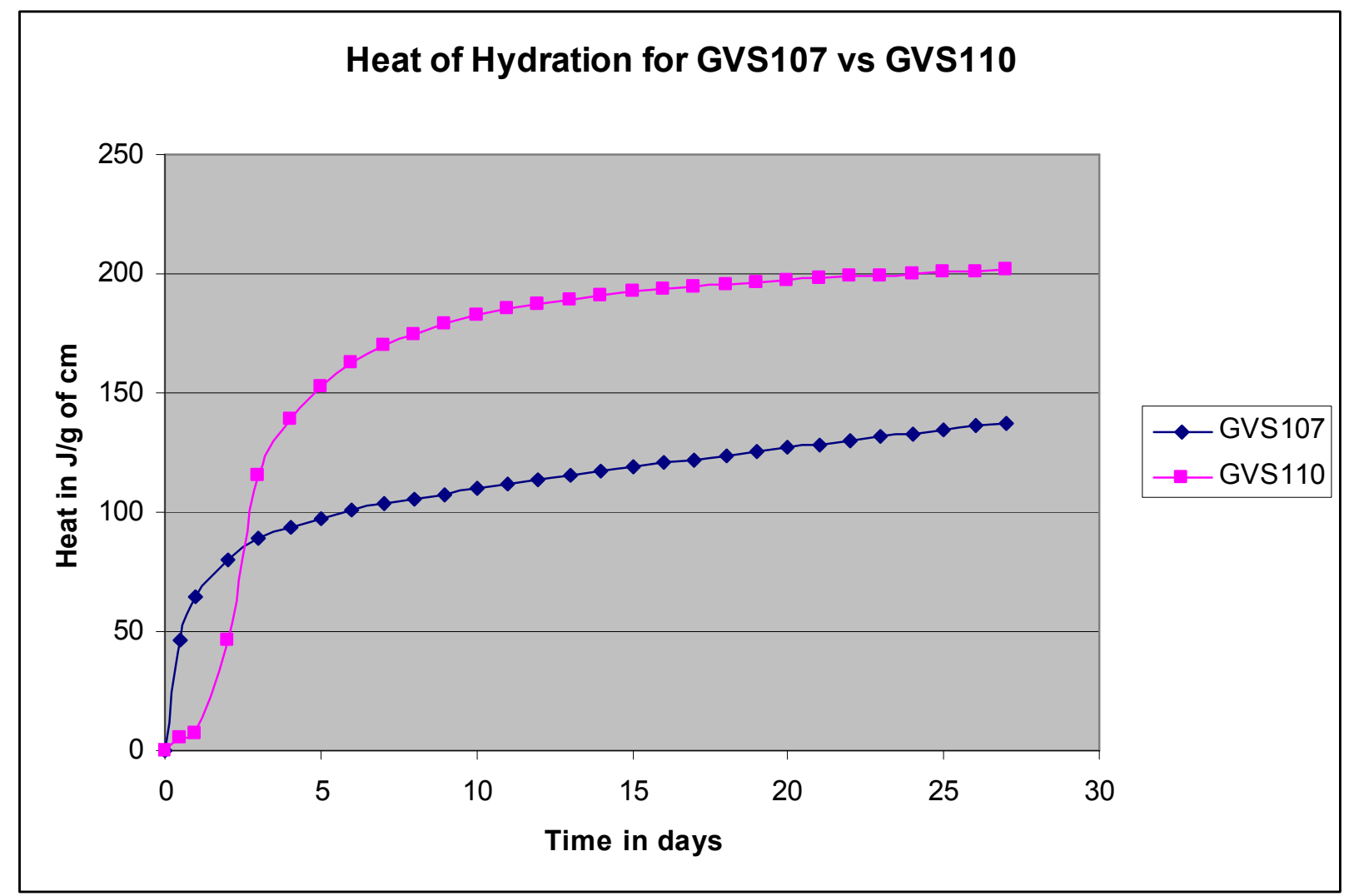

Figure 3-1 Comparison of the heat of hydration for GVS107 and GVS110.

The fresh and cured grout properties of these two mixes are presented in Table 3-2. The induction period in the heat of hydration for GVS110 is also reflected in the 3 day set time for GVS110 as compared to the 1 day set time for GVS107. The higher aluminate mix also has a Young's modulus value that is more that double the value of $\mathrm{E}$ for the $0.05 \mathrm{M}$ aluminate mix consistent with the higher heat of hydration.

Table 3-2 Fresh and Cured Grout Properties for GVS107 and GVS110.

\begin{tabular}{|c|c|c|c|c|c|c|c|c|}
\hline \multirow[b]{2}{*}{ Identifier } & & \multirow{2}{*}{$\begin{array}{c}\text { Fresh } \\
\text { Density }\end{array}$} & \multirow{2}{*}{$\begin{array}{l}\text { Cured } \\
\text { Density }\end{array}$} & \multirow[b]{2}{*}{ Flow } & \multirow[b]{2}{*}{ Yield Stress } & \multirow[b]{2}{*}{ Viscosity } & \multirow[b]{2}{*}{ Bleed } & \multirow[b]{2}{*}{ Set Time } \\
\hline & Gel Time & & & & & & & \\
\hline & minutes & $\mathrm{g} / \mathrm{mL}$ & $\mathrm{g} / \mathrm{mL}$ & inches & $\mathrm{Pa}$ & $\mathrm{cP}$ & Vol \% & Days \\
\hline GVS107 & 30 & 1.717 & 1.753 & 21.4 & 6.2 & 98.4 & 0.0 & 1.0 \\
\hline \multirow[t]{3}{*}{ GVS110 } & 30 & 1.722 & 1.750 & 23.3 & 4.7 & 89.5 & 0.5 & 3.0 \\
\hline & Porosity & Heat & $\bar{E}$ & & & & & \\
\hline & Volume \% & $\mathrm{J} / \mathrm{g} \mathrm{cm}$ & $\mathrm{GPa}$ & & & & & \\
\hline GVS107 & 59.1 & 139.0 & 4.2 & & & & & \\
\hline GVS110 & 57.2 & 202.0 & 8.8 & & & & & \\
\hline
\end{tabular}




\subsection{Phase 10 - Young's Modulus as a Function of w/cm Ratio and Wt \% BFS}

The values of Young's moduli for the eight ARP/MCU mixes for Phase 10 (GVS108 -

GVS115) as a function of w/cm ratio at two different slag loadings are presented in Figure 3-2. These samples were cured under sealed conditions at room temperature $\left(22^{\circ} \mathrm{C}\right)$. It is clear from these data that decreasing the $\mathrm{w} / \mathrm{cm}$ ratio from 0.65 to 0.50 increases Young's modulus by $\sim 25$ $\%$ independent of the slag loading. Based on literature values of Young's modulus, this increase in E can be associated with significant changes in the permeability. The second conclusion that can be drawn from these data is that an increase in wt \% slag from 45 to $60 \mathrm{wt} \%$ in the mixes at the expense of fly ash increases Young's modulus by $\sim 12 \%$. Therefore, by reducing the w/cm ratio and/or increasing the wt \% slag content, an improvement in performance as measured by Young's modulus can be achieved for room temperature cured samples. As previously discussed, there is also an increase in Young's modulus for the samples as a result of an increase in the aluminate level from $0.05 \mathrm{M}$ in the previous baseline to $0.22 \mathrm{M}$ in the current baseline.

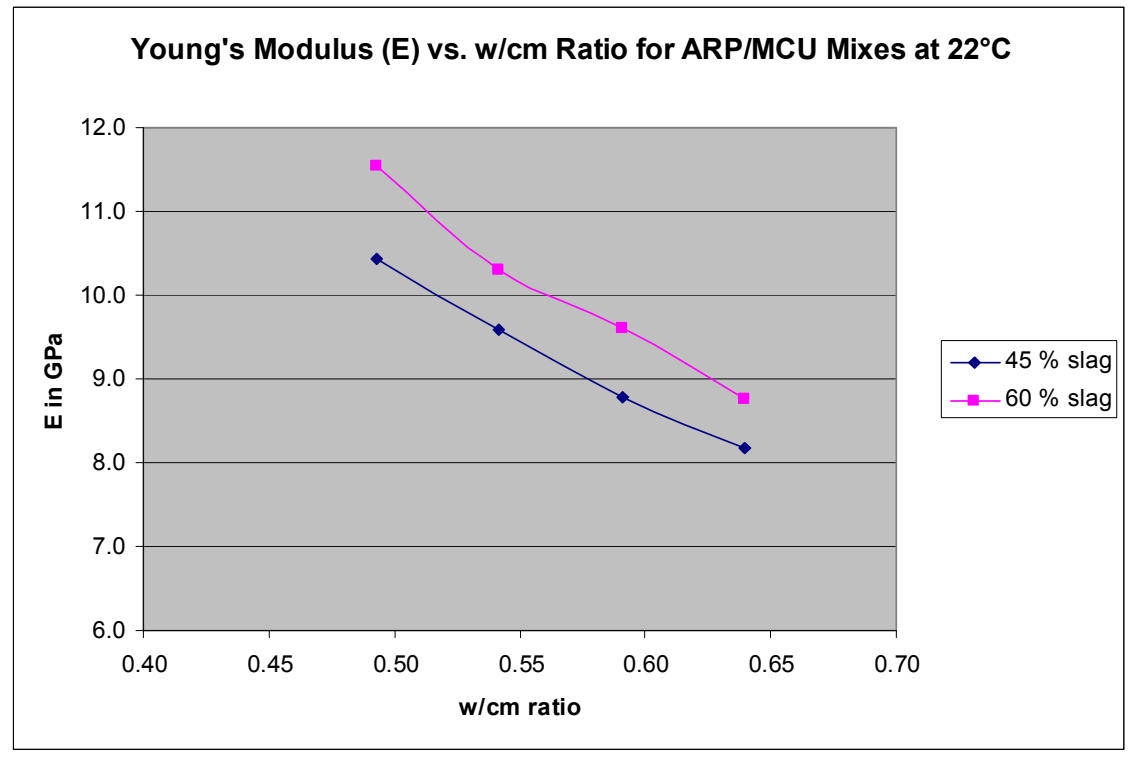

Figure 3-2 Young's modulus (E) values for eight ARP/MCU mixes as a function of w/cm ratio and wt \% slag for samples cured at $22{ }^{\circ} \mathrm{C}$.

The time dependence of Young's Modulus for the mixes cured at $22{ }^{\circ} \mathrm{C}$ is provided in Figure 33. These results reveal that the mixes in general continue to hydrate with time over the span of the measurements. 


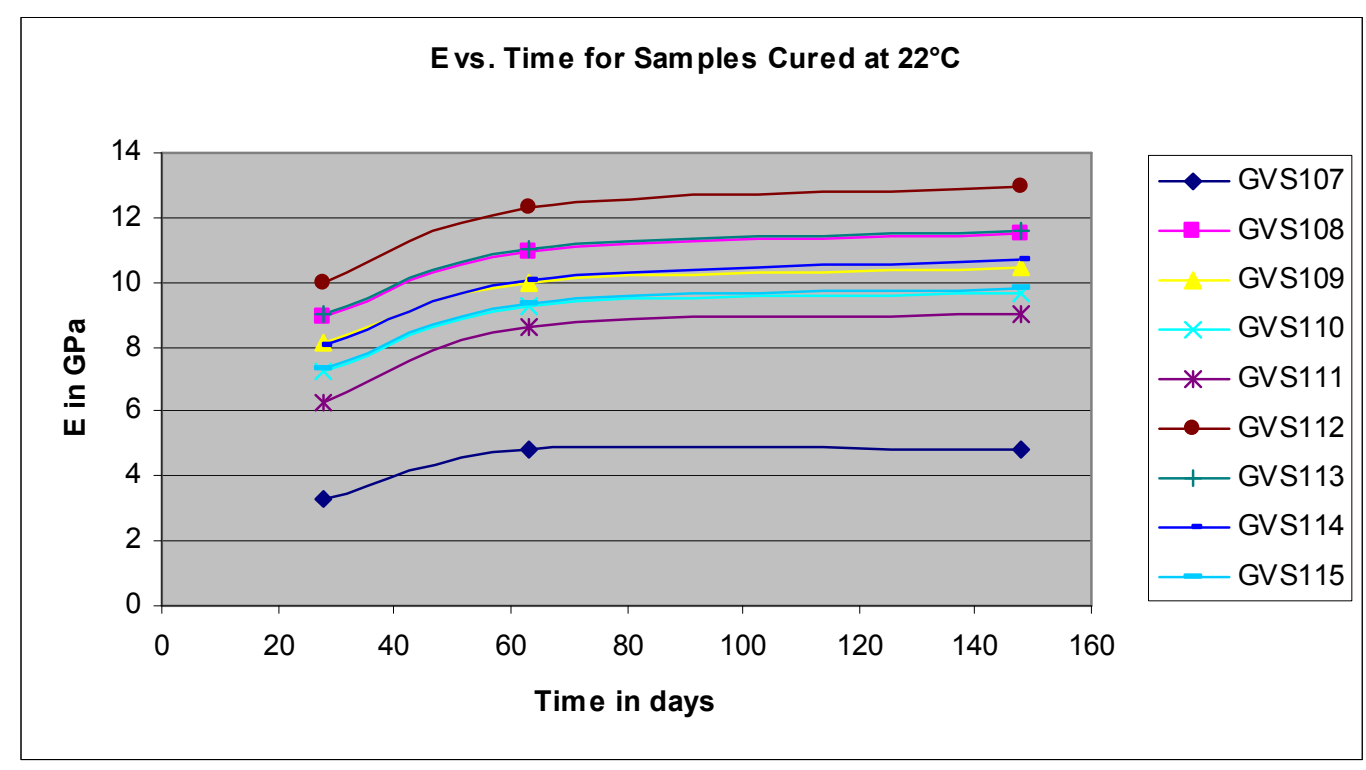

Figure 3-3 Time dependence of $E$ for nine ARP/MCU mixes as a function of $\mathrm{w} / \mathrm{cm}$ ratio and wt \% slag for samples cured at $22{ }^{\circ} \mathrm{C}$.

Samples of these mixes were also cured in sealed cylinders in ovens at $40{ }^{\circ} \mathrm{C}$ and $54{ }^{\circ} \mathrm{C}$ for 28 days to determine the impact of curing temperature on the performance properties of Saltstone. One additional sample was cured at $54{ }^{\circ} \mathrm{C}$ for 1 week, removed from the oven and then cured for the remaining 21 days at ambient temperature. The values for the 28 day Young's modulus for each of these samples at two different slag concentrations (45 wt \% and $60 \mathrm{wt} \%$ ) are provided in Figure 3-4.
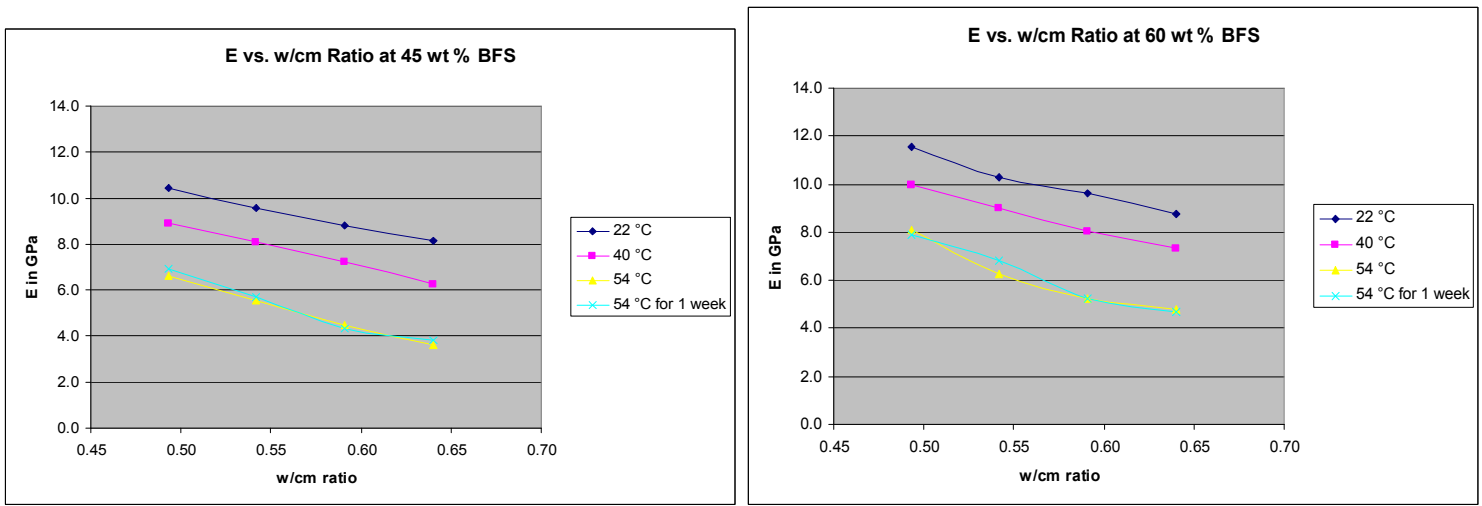

Figure 3-4 Young's modulus values for ARP/MCU mixes containing 45 or 60 wt \% slag after curing at the indicated temperatures for 28 days. The data points for the cyan colored $x$ 's were obtained on the samples removed from the $54{ }^{\circ} \mathrm{C}$ oven at 1 week and measured at 28 days.

The data in Figure 3-4 reveal that E values are significantly reduced at higher curing temperatures. Furthermore, the E values for the samples initially cured at $54{ }^{\circ} \mathrm{C}$ for one week and then removed and cured at ambient temperature are essentially identical to the samples cured 
for the entire 28 days at $54{ }^{\circ} \mathrm{C}$. This implies that no further hydration reactions occurred after one week of curing at $54{ }^{\circ} \mathrm{C}$.

The time dependence of $\mathrm{E}$ for Samples cured at $40{ }^{\circ} \mathrm{C}$ and $54{ }^{\circ} \mathrm{C}$ for 28 days and then removed and stored in sealed containers under ambient temperatures are provided in Figure 3-5. Unlike the samples cured at $22^{\circ} \mathrm{C}$ (Figure 3-3), the hydration reactions in the samples cured at higher temperatures change very little with time.
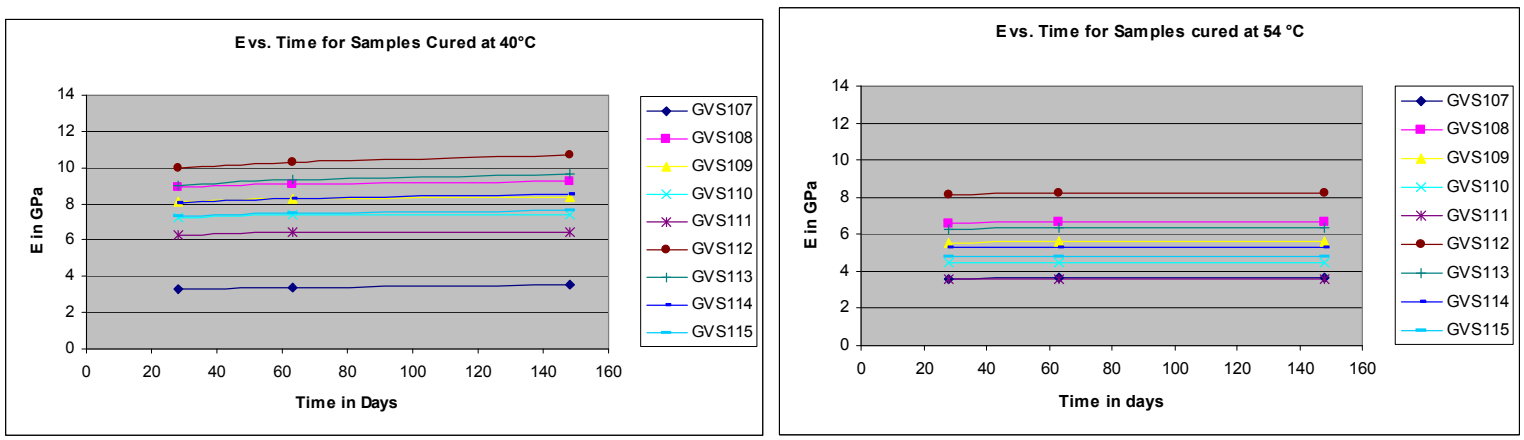

Figure 3-5 Time dependence of $\mathrm{E}$ for samples cured at either $40{ }^{\circ} \mathrm{C}$ or $54{ }^{\circ} \mathrm{C}$ for 28 days and then removed, sealed and stored at ambient temperature.

\subsection{Young's Modulus at Different Time/Temperature Curing Profiles}

Previous results [4] have shown that the performance properties of the mixes depend on the time/temperature profile for curing. Figure 3-6 shows the dependence of $E$ on time and temperature curing profile for a mix at $0.55 \mathrm{w} / \mathrm{cm}$ ratio and $45 \mathrm{wt} \% \mathrm{slag}$ (GVS109). The time/temperature curing profile for each curve is provided in the chart below the figure. The data show that an increase in temperature to $54{ }^{\circ} \mathrm{C}$ after 1 through 4 days curing at $22{ }^{\circ} \mathrm{C}$ essentially stops any further hydration. Therefore, a mix that has cured for only one day at $22^{\circ} \mathrm{C}$ prior to curing at an elevated temperature does not reach as high an $\mathrm{E}$ value as a mix which is allowed to remain at $22{ }^{\circ} \mathrm{C}$ for 3 days. For mixes cured initially at $54{ }^{\circ} \mathrm{C}$, removal after 1 or 2 days at $54{ }^{\circ} \mathrm{C}$ results in mixes with lower E values than the mix cured for 7 days at $54{ }^{\circ} \mathrm{C}$. Therefore, any change in curing temperature (from $54{ }^{\circ} \mathrm{C}$ to $22{ }^{\circ} \mathrm{C}$ or from $22{ }^{\circ} \mathrm{C}$ to $54{ }^{\circ} \mathrm{C}$ ) results in lower $\mathrm{E}$ values than achieved by curing over the entire time at one temperature.

Figure 3-7 shows the results for curing temperature profiles at $40{ }^{\circ} \mathrm{C}$ and $75^{\circ} \mathrm{C}$. The samples cured at $75^{\circ} \mathrm{C}$ had the lowest values of $\mathrm{E}$. Those samples cured at $40^{\circ} \mathrm{C}$ had $\mathrm{E}$ values between the values for samples cured at $22^{\circ} \mathrm{C}$ and the values for samples cured at $54{ }^{\circ} \mathrm{C}$. 


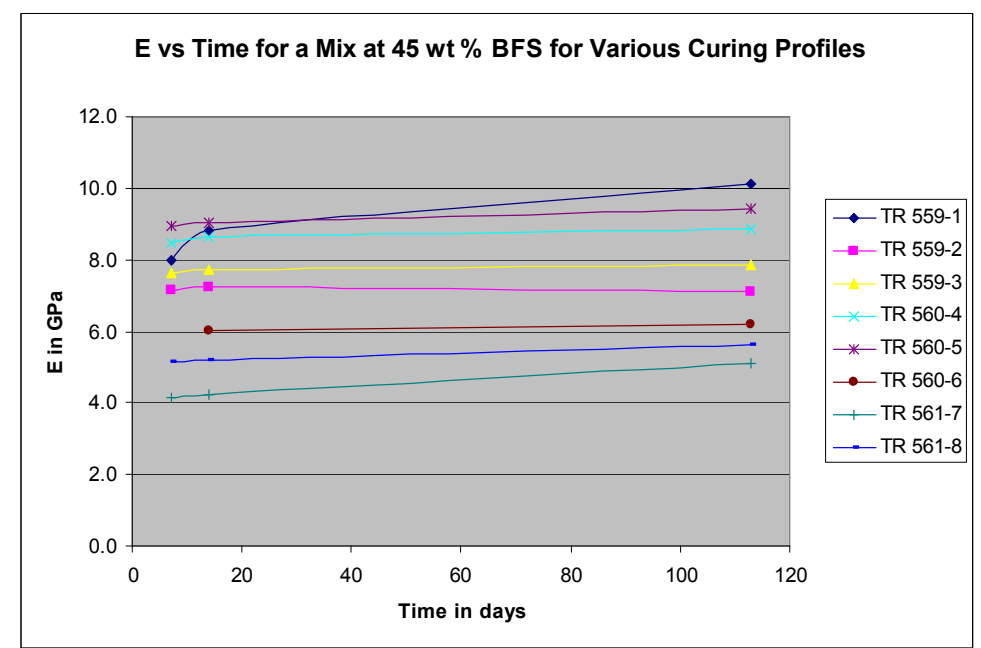

\begin{tabular}{|c|c|c|c|}
\hline TR \# & Time/ Temperature Profile & TR \# & Time/ Temperature Profile \\
\hline TR 559-1 & Curing only at $22^{\circ} \mathrm{C}$ & TR $560-5$ & 4 days at $22{ }^{\circ} \mathrm{C}$ and 3 days at $54{ }^{\circ} \mathrm{C}$ \\
\hline TR 559-2 & 1 day at $22{ }^{\circ} \mathrm{C}$ and 6 days at $54{ }^{\circ} \mathrm{C}$ & TR $560-6$ & 7 days at $54{ }^{\circ} \mathrm{C}$ \\
\hline TR 559-3 & 2 days at $22{ }^{\circ} \mathrm{C}$ and 5 days at $54{ }^{\circ} \mathrm{C}$ & TR $561-7$ & 1 day at $54{ }^{\circ} \mathrm{C}$ and 6 days at $22{ }^{\circ} \mathrm{C}$ \\
\hline TR 560-4 & 3 days at $22{ }^{\circ} \mathrm{C}$ and 4 days at $54{ }^{\circ} \mathrm{C}$ & TR $561-8$ & 2 days at $54{ }^{\circ} \mathrm{C}$ and 5 days at $22{ }^{\circ} \mathrm{C}$ \\
\hline
\end{tabular}

Figure 3-6 Time dependence of E in GPa for GVS109 (45 wt \% slag) at indicated time and temperature profiles.

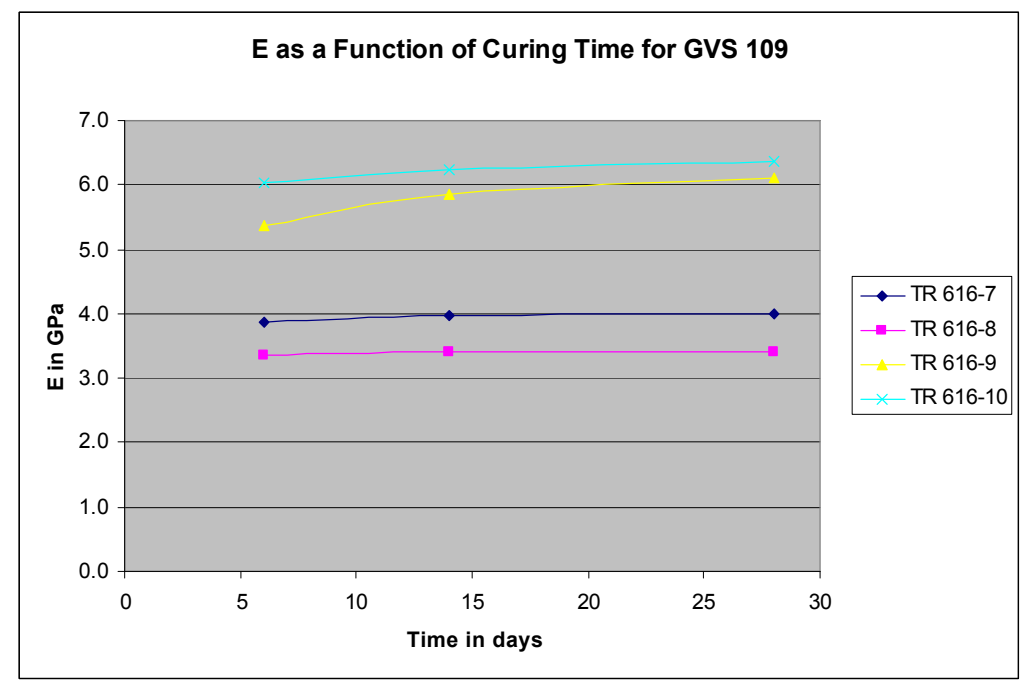

\begin{tabular}{|l|c|}
\hline \multicolumn{1}{|c|}{ TR \# } & Time/ Temperature Profile \\
\hline TR $616-7$ & 7 days at $75^{\circ} \mathrm{C}$ \\
\hline TR $616-8$ & 1 day at $75^{\circ} \mathrm{C}$ and 6 days at $22^{\circ} \mathrm{C}$ \\
\hline TR $616-9$ & 1 day at $40^{\circ} \mathrm{C}$ and 6 days at $22^{\circ} \mathrm{C}$ \\
\hline TR $616-10$ & 7 days at $40^{\circ} \mathrm{C}$ \\
\hline
\end{tabular}

Figure 3-7 Time dependence of E in GPa for GVS109 (45 wt \% slag) at indicated time and temperature profiles. 
Similar results were obtained for the mixes containing $60 \mathrm{wt} \%$ BFS (GVS113) under the same set of time and temperature profiles (see Figure 3-8).

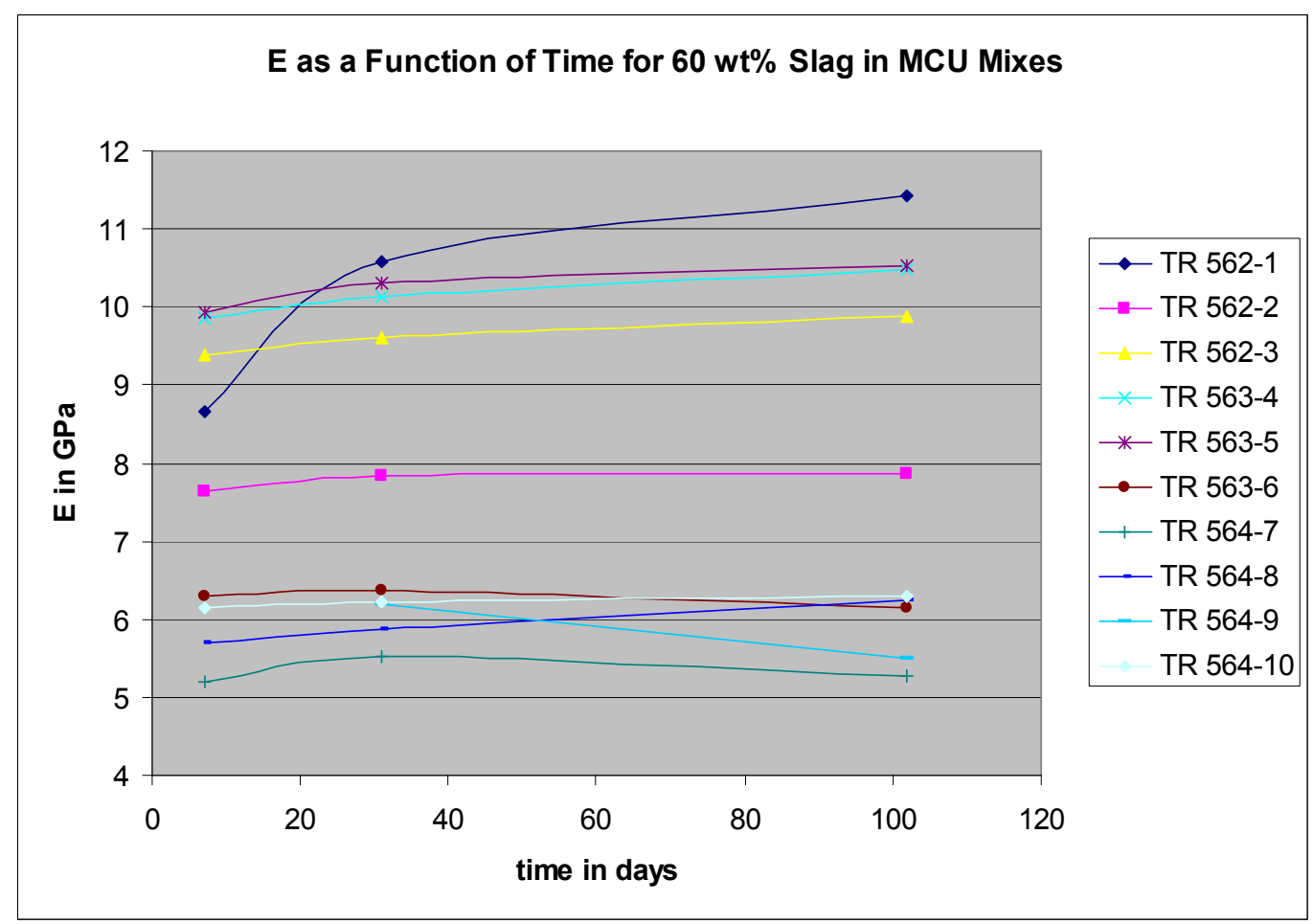

\begin{tabular}{|c|c|c|c|}
\hline TR \# & Time/ Temperature Profile & TR \# & Time/ Temperature Profile \\
\hline TR 562-1 & Curing only at $22{ }^{\circ} \mathrm{C}$ & TR $563-6$ & 7 days at $54{ }^{\circ} \mathrm{C}$ \\
\hline TR 562-2 & 1 day at $22{ }^{\circ} \mathrm{C}$ and 6 days at $54{ }^{\circ} \mathrm{C}$ & TR $564-7$ & 1 day at $54{ }^{\circ} \mathrm{C}$ and 6 days at $22{ }^{\circ} \mathrm{C}$ \\
\hline TR 562-3 & 2 days at $22^{\circ} \mathrm{C}$ and 5 days at $54{ }^{\circ} \mathrm{C}$ & TR $564-8$ & 2 days at $54{ }^{\circ} \mathrm{C}$ and 5 days at $22^{\circ} \mathrm{C}$ \\
\hline TR 563-4 & 3 days at $22^{\circ} \mathrm{C}$ and 4 days at $54{ }^{\circ} \mathrm{C}$ & TR $564-9$ & 3 days at $54{ }^{\circ} \mathrm{C}$ and 4 days at $22{ }^{\circ} \mathrm{C}$ \\
\hline TR 563-5 & 4 days at $22{ }^{\circ} \mathrm{C}$ and 3 days at $54{ }^{\circ} \mathrm{C}$ & TR $564-10$ & 4 days at $54{ }^{\circ} \mathrm{C}$ and 3 days at $2{ }^{\circ} \mathrm{C}$ \\
\hline
\end{tabular}

Figure 3-8 Time dependence of E in GPa for GVS113 (0.55 w/cm ratio and $60 \mathrm{wt} \% \mathrm{slag})$ at indicated time and temperature profiles.

\subsection{Porosities as a Function of Curing Temperature and Time}

The impact of $\mathrm{w} / \mathrm{cm}$ ratio and slag content on total porosity, $\Phi$, was determined for the Phase 10 ARP/MCU mixes at $0.50,0.55,0.60$, and $0.65 \mathrm{w} / \mathrm{cm}$ ratios for premixes containing either 45 or $60 \mathrm{wt} \% \mathrm{slag}$. The total porosity values (expressed as fractions) for samples cured at $22{ }^{\circ} \mathrm{C}$ are shown in Figure 3-9. The total porosity decreases with (1) decreasing w/cm ratio and (2) increasing slag content. This is consistent (porosity and E are inversely related [9, 10]) with the trend of Young's Modulus values for these same mixes as shown in Figure 3-2. 


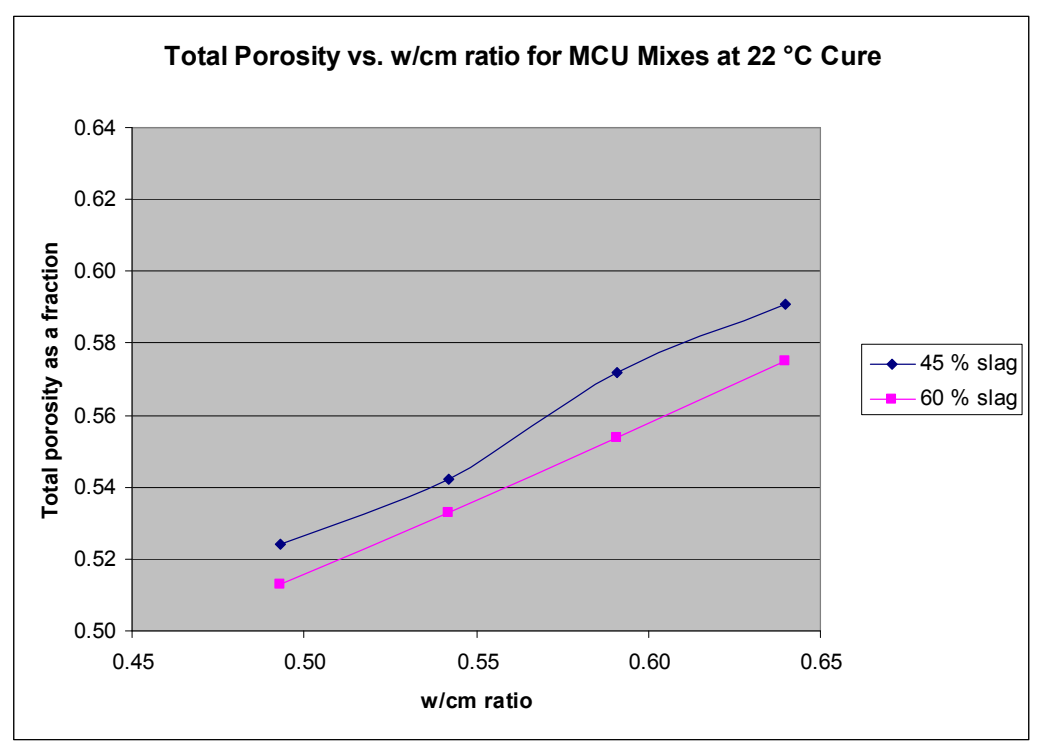

Figure 3-9 Total porosity for mixes batched with either 45 or $60 \mathrm{wt} \%$ slag as a function of w/cm ratio. Porosities were measured after 28 days of curing at $22{ }^{\circ} \mathrm{C}$.

Figure 3-10 shows the dependence of total porosity on curing temperature for samples that contain 45 and $60 \mathrm{wt} \%$ slag in the premix. The total porosity increases with increasing curing temperature which again, as expected by the inverse relationship between E and porosity, corresponds to the data obtained for Young's modulus over these variables (Figure 3-2). The correlation of E and $\Phi$ is discussed in Section 3-11.
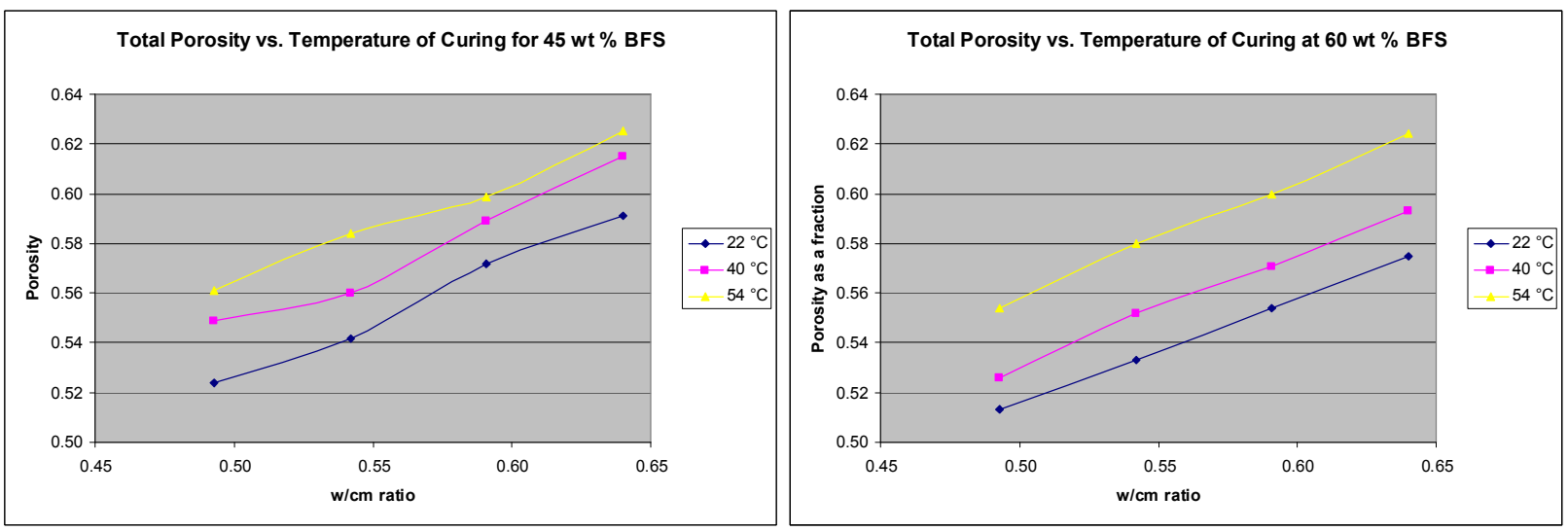

Figure 3-10 Total porosity as a function of $w / \mathrm{cm}$ ratio for 3 cure temperatures.

\subsection{Heat of Hydration}

The heat of hydration data for Phase 10 mixes are provided in Table 3-3. As the w/cm ratio increases for both the 45 and $60 \mathrm{wt} \%$ slag mixes, the heat of hydration normalized to the premix 
content actually increases slightly except for the $\mathrm{w} / \mathrm{cm}$ ratio mix of 0.50 for both slag mixes. However, the heat of hydration normalized to the amount of grout is essentially the same for mixes with $45 \mathrm{wt} \%$ BFS $(\sim 110 \mathrm{~J} / \mathrm{g})$ and $60 \mathrm{wt} \% \mathrm{BFS}(\sim 140 \mathrm{~J} / \mathrm{g})$. The difference in heat generation between these two sets is mainly due to the differences in slag content. The empirical model developed and discussed in Section 5 of this report details the dependence of heat of hydration on the significant factors for the combined 10 and 11 phases.

Table 3-3 Heat of Hydration and Peak Time for Heat Generation for Phase 10 Mixes

\begin{tabular}{|c|c|c|c|c|}
\hline Identifier & Channel \# & Heat of Hydration & Heat of Hydration & Peak time \\
\hline & & $\mathrm{J} / \mathrm{g}$ of premix & $\mathrm{J} / \mathrm{g}$ of grout & hours \\
\hline GVS107 & 6 & 139 & 76 & 4 \\
\hline GVS108 & 1 & 211 & 125 & 37 \\
\hline GVS109 & 2 & 190 & 107 & 43 \\
\hline GVS110 & 3 & 202 & 110 & 48 \\
\hline GVS111 & 4 & 210 & 110 & 52 \\
\hline GVS112 & 5 & 250 & 147 & 24 \\
\hline GVS113 & 6 & 250 & 141 & 29 \\
\hline GVS114 & 7 & 258 & 140 & 26 \\
\hline GVS115 & 8 & 268 & 135 & 29 \\
\hline
\end{tabular}

\subsection{Electron Microscopy}

In an effort to better understand the microstructure of these mixes as a function of temperature, samples were submitted for imaging by Scanning Electron Microscopy (SEM). Figure 3-11 shows the electron micrographs of GVS11 cured at $22{ }^{\circ} \mathrm{C}$ and $54{ }^{\circ} \mathrm{C}$. These samples were polished first and then imaged using Back-Scattered Electrons (BSE) with SEM at Clemson University. The top image is for the sample cured at $22{ }^{\circ} \mathrm{C}$ and shows individual particles including the spherical fly ash particles. The bottom image in Figure 3-11 was cured at $54{ }^{\circ} \mathrm{C}$ and shows a different morphology. Chemical analyses of selected regions were performed by energy dispersive X-ray techniques. These results are preliminary only and have not been duplicated or validated by other samples since funding for this task was stopped after the first set of data was acquired. Nevertheless, the results are revealing, show the power of the technique to characterize these samples, and have the potential to provide insight into the hydration products as a function of curing temperature. It is recommended that additional SEM characterization of the samples as a function of temperature of curing and aluminate concentration in the salt solution be performed in FY10. 
Rev. 0
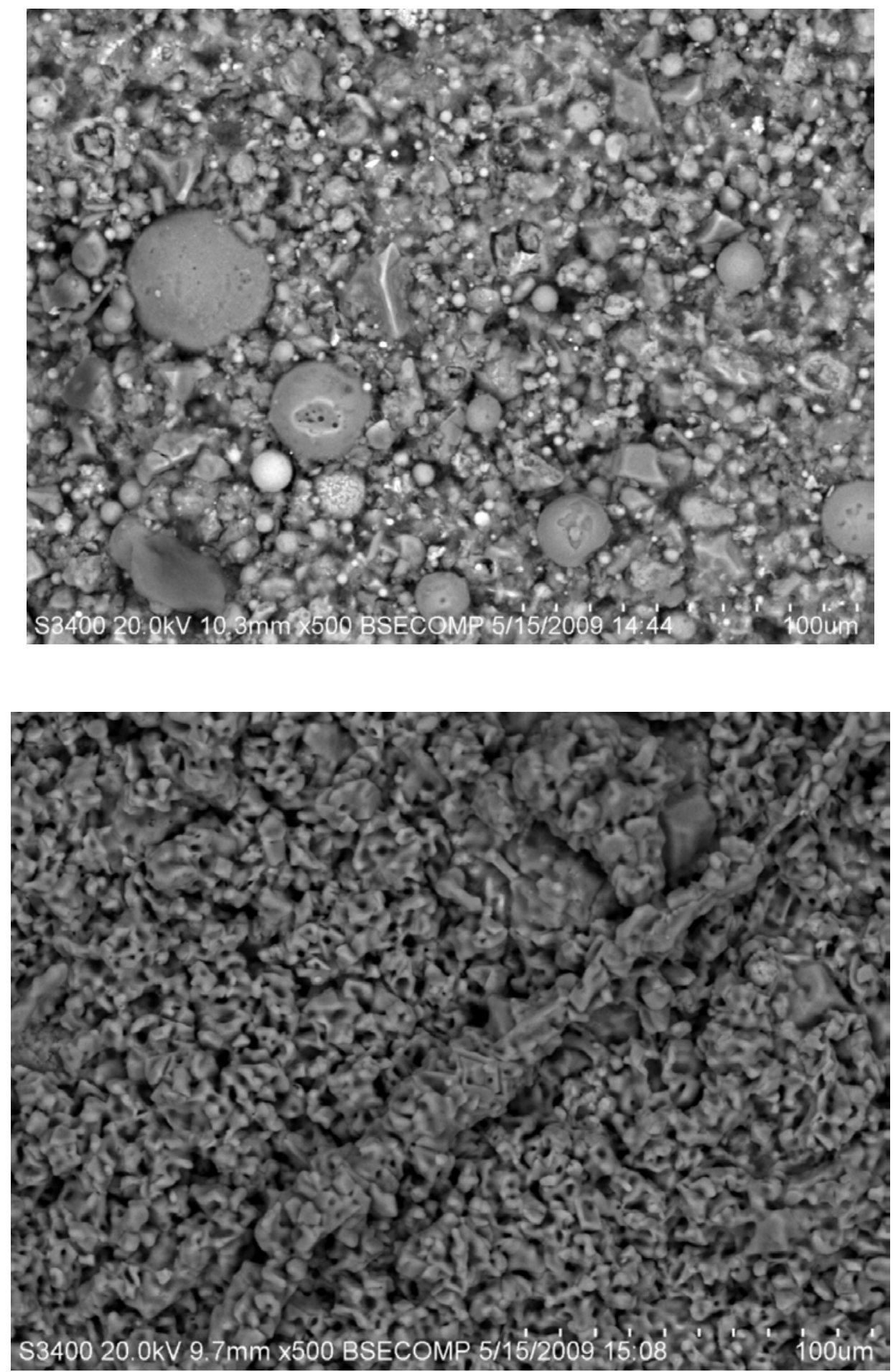

Figure 3-11 BSE micrographs of polished samples of GVS11 cured at $22^{\circ} \mathrm{C}$ (top image) and $54^{\circ} \mathrm{C}$ (bottom image). 


\subsection{Processing Properties}

Task 3 focused mainly on the performance properties of the ARP/MCU Saltstone mixes. However, the processing properties must also be acceptable for processing at SPF. The processing property results for Phase 10 mixes are presented in Table 3-4. Three of the mixes had gel times reported as 10 minutes (the mixes had gelled at 20 minutes so the real gel time is between 10 and 20 minutes). These short gel times were associated with the 3 mixes at the low $\mathrm{w} / \mathrm{cm}$ ratios $(0.50$ and 0.55$)$ and 2 of these 3 mixes had $60 \mathrm{wt} \%$ slag content. The lower $\mathrm{w} / \mathrm{cm}$ ratio mixes also had relatively high yield stress and plastic viscosity values. Acceptance criteria for the flow properties have yet to be established and pumping calculations will be required to determine these criteria. At $22{ }^{\circ} \mathrm{C}$, there was a small amount of bleed on some of the mixes at 1 day but no bleed was evident on any of the mixes at 3 days. For these mixes cured at either 40 ${ }^{\circ} \mathrm{C}$ or $60{ }^{\circ} \mathrm{C}$ there was no bleed water at 1 day. Set times for the $0.22 \mathrm{M}$ aluminate mixes were either 2 or 3 days at $22^{\circ} \mathrm{C}$, and less than 1 day when cured at the higher temperatures.

Table 3-4 Processing Properties for Phase 10 Mixes.

\begin{tabular}{|c|c|c|c|c|c|c|c|c|c|c|c|c|c|}
\hline \multirow[b]{2}{*}{ Identifier } & \multirow[b]{2}{*}{ Gel Time } & \multirow{2}{*}{$\begin{array}{c}\text { Fresh } \\
\text { Density }\end{array}$} & \multirow{2}{*}{$\begin{array}{l}\text { Cured } \\
\text { Density }\end{array}$} & \multirow[b]{2}{*}{ Flow } & \multicolumn{2}{|c|}{ Uncorrected } & \multicolumn{3}{|c|}{ 1-Day Bleed } & \multirow{2}{*}{$\frac{\text { 3-Day Bleed }}{22^{\circ} \mathrm{C}}$} & \multicolumn{3}{|c|}{ Set Time } \\
\hline & & & & & \begin{tabular}{|l|} 
Yield Stress \\
\end{tabular} & Viscosity & $22^{\circ} \mathrm{C}$ & $40^{\circ} \mathrm{C}$ & $60^{\circ} \mathrm{C}$ & & $22^{\circ} \mathrm{C}$ & $40^{\circ} \mathrm{C}$ & $60^{\circ} \mathrm{C}$ \\
\hline & minutes & $\mathrm{g} / \mathrm{mL}$ & $\mathrm{g} / \mathrm{mL}$ & $\mathrm{cm}$ & $\mathrm{Pa}$ & $\mathrm{cP}$ & Vol \% & Vol \% & Vol \% & Vol \% & Days & Days & Days \\
\hline GVS107 & 30 & 1.719 & 1.753 & 21.4 & 6.2 & 98.4 & 0.0 & 0.0 & 0.0 & 0.0 & 1 & 1 & 1 \\
\hline GVS108 & 10 & 1.791 & 1.827 & 18.2 & 11.0 & 206.5 & 0.3 & 0.0 & 0.0 & 0.0 & 2 & 1 & 1 \\
\hline GVS109 & 20 & 1.751 & 1.784 & 20.9 & 6.3 & 125.2 & 0.4 & 0.0 & 0.0 & 0.0 & 2 & 1 & 1 \\
\hline GVS110 & 30 & 1.722 & 1.750 & 23.3 & 4.7 & 89.5 & 0.6 & 0.0 & 0.0 & 0.0 & 3 & 1 & 1 \\
\hline GVS111 & 30 & 1.710 & 1.734 & 25.3 & 3.0 & 58.4 & 0.9 & 0.8 & 0.0 & 0.0 & 3 & 1 & 1 \\
\hline GVS112 & 10 & 1.818 & 1.862 & 17.7 & 14.9 & 213.2 & 0.0 & 0.0 & 0.0 & 0.0 & 2 & 1 & 1 \\
\hline GVS113 & 10 & 1.777 & 1.831 & 20.4 & 8.7 & 128.9 & 0.3 & 0.0 & 0.0 & 0.0 & 2 & 1 & 1 \\
\hline GVS114 & 25 & 1.744 & 1.791 & 23.0 & 5.7 & 88.2 & 0.5 & 0.0 & 0.0 & 0.0 & 2 & 1 & 1 \\
\hline GVS115 & 20 & 1.714 & 1.768 & 25.0 & 4.3 & 64.6 & 0.5 & 0.0 & 0.0 & 0.0 & 2 & 1 & 1 \\
\hline
\end{tabular}

\subsection{Drying Shrinkage and Cracking}

Cast samples of GVS107 through GVS115 were removed from the plastic cylinders and placed in an oven at $40{ }^{\circ} \mathrm{C}$ for a period of several months. The mass losses due to water evaporation are shown in Figure 3-12. GVS107 is the only sample with low $(0.05 \mathrm{M})$ aluminate and this sample exhibited a unique mass loss curve relative to the other mixes (with aluminate at $0.22 \mathrm{M}$ ). These losses overall are substantial and approach the values of mass loss that have been measured for the porosity tests in which the samples are heated to $105{ }^{\circ} \mathrm{C}$ until no further change in mass occurs. The longer times required for mass loss of the cylinders are due to the differences in (1) surface area (the porosity measurements are carried out with a crushed sample) and (2) temperature of drying $\left(40^{\circ} \mathrm{C}\right.$ vs. $\left.105^{\circ} \mathrm{C}\right)$. 


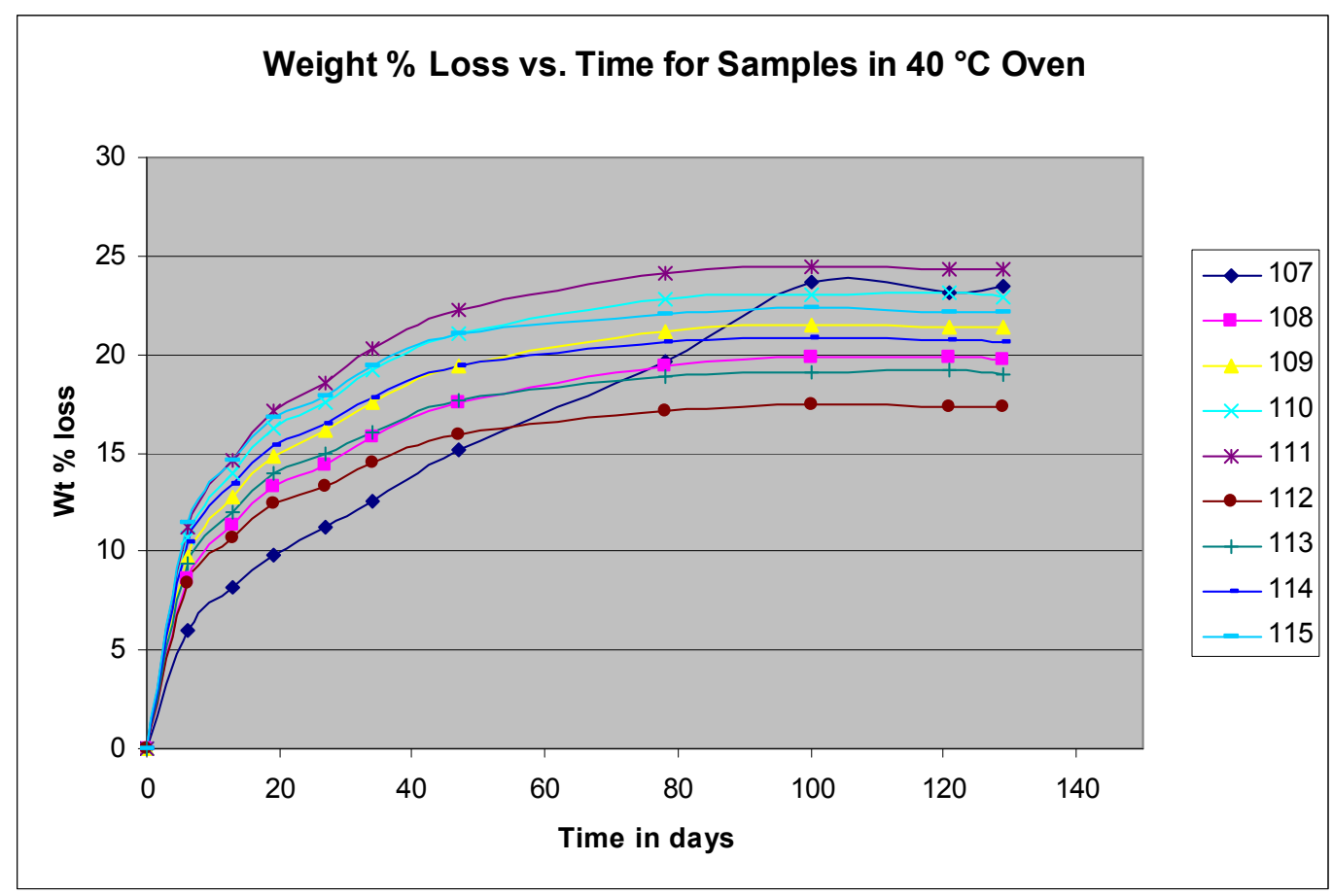

Figure 3-12 Wt \% loss of GVS samples numbered 107 through 115 as a function of time in the $40{ }^{\circ} \mathrm{C}$ oven.

A photograph of the GVS107 after drying is shown in the left side of Figure 3-13. The photo to the right of this in Figure 3-13 is the sample after being broken by a blow from a hammer. In this case the cylinder broke apart into several large pieces with relatively smooth surfaces. This is in contrast to the other 8 samples of Phase 10 which exhibited a different outcome after being broken. 
Rev. 0

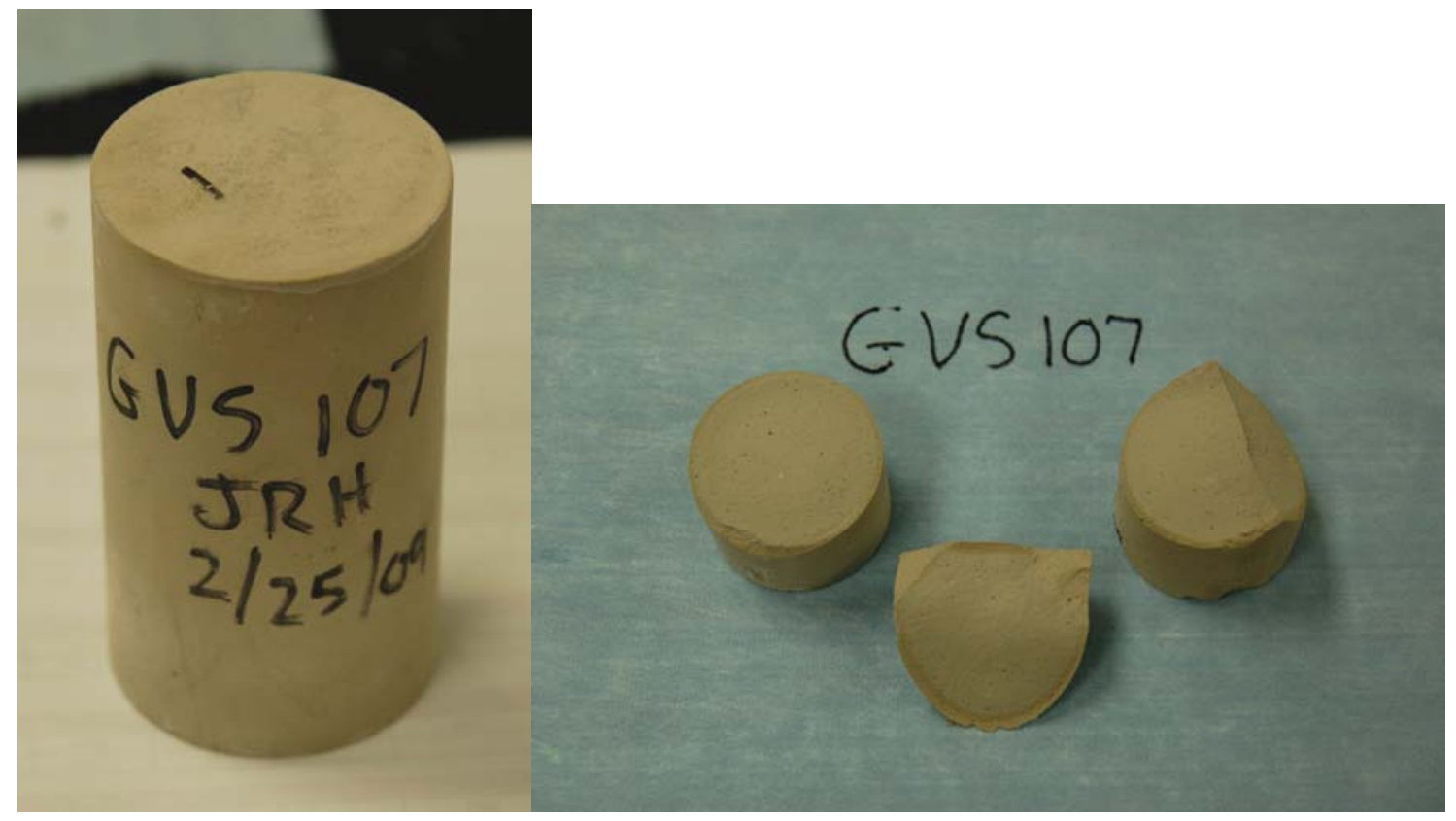

Figure 3-13 GVS107 after drying (image on the left) and then after being broken apart.

The samples from GVS108 through GVS115 showed evidence of surface cracking after drying at $40{ }^{\circ} \mathrm{C}$. The cylinders were broken apart with a hammer which resulted in a crushed material with jagged edges reflective of cleavage along the cracks (Figures 3-14 and 3-15).

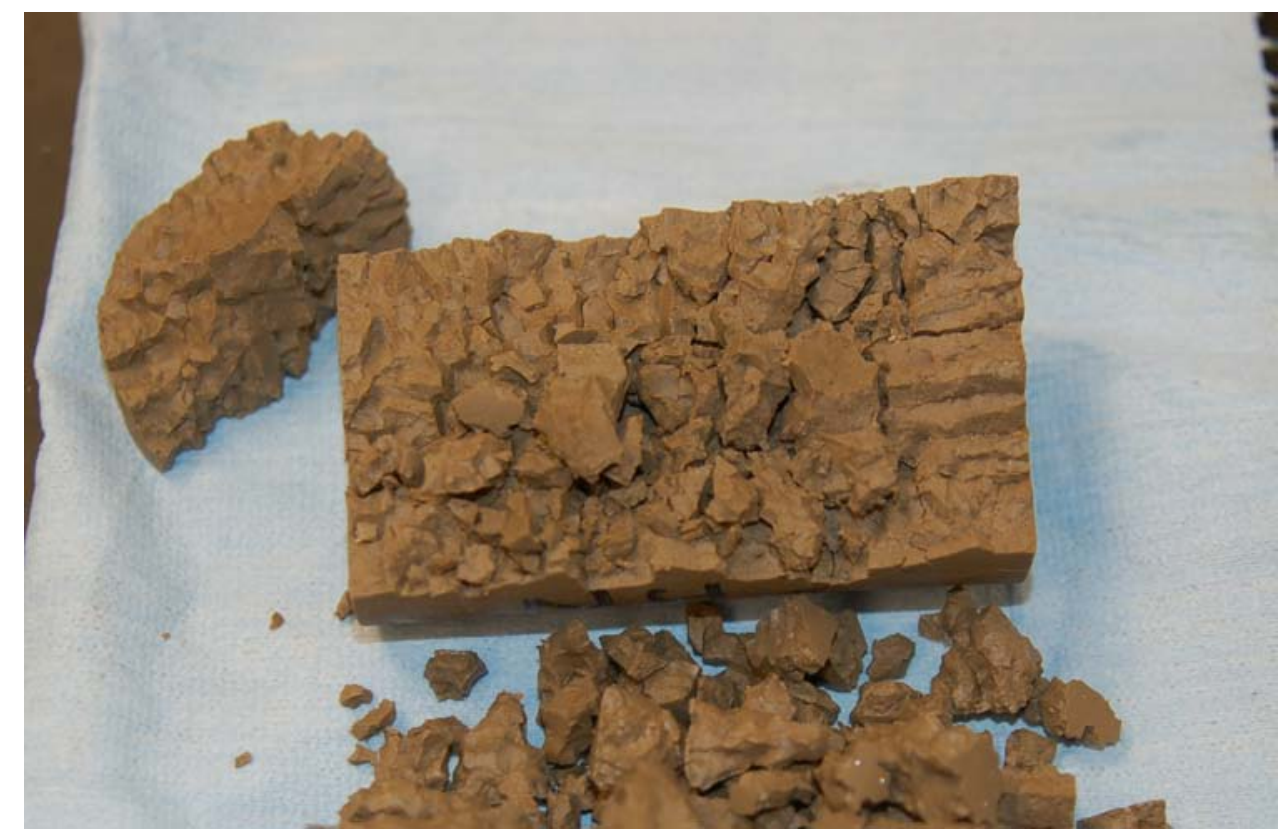

Figure 3-14 Cast cylinder of GVS111 after rehydration and cracking. 


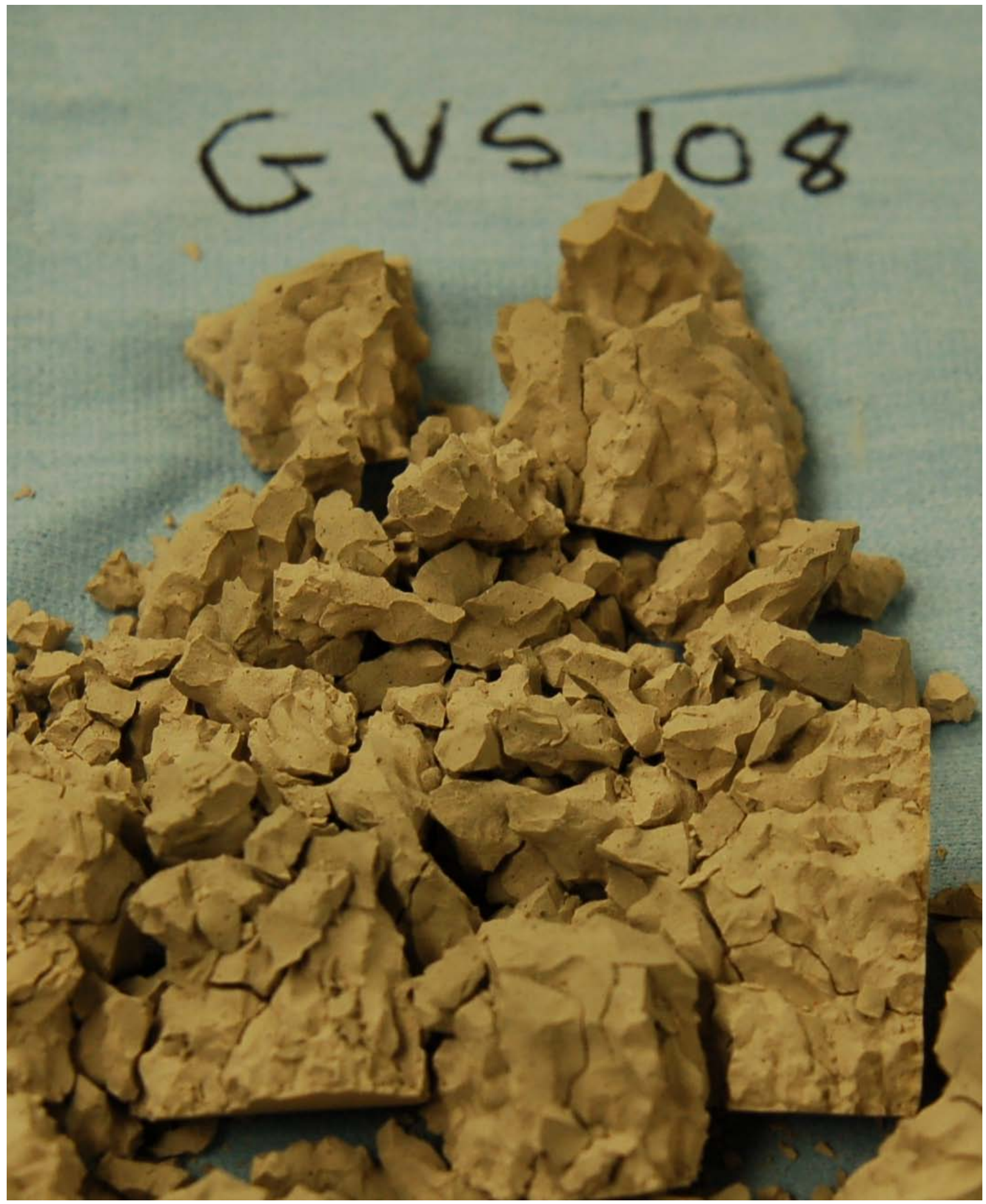

Figure 3-15 Cast cylinder of GVS108 after rehydration and broken apart using a hammer. 
Several cured samples were partially dried resulting in a $\sim 10 \mathrm{wt} \%$ decrease as a result of water loss. Subsequent breaking of these cylindrical samples resulted in a circular cross section that revealed two distinct regions. Figure 3-16 provides an example of a 2 inch diameter cast cylinder that was partially dried and then broken by hand. This example is for a mix containing $\mathrm{BFS}$ at $0.60 \mathrm{w} / \mathrm{cm}$ ratio in $3.0 \mathrm{M} \mathrm{NaOH}$. There was an inner core that was intact, saturated, and blue in color (typical of samples containing slag) with no evidence of cracking. The outer surface was completely dried, white, and highly cracked as evidenced by the fractured surface. It appears that the samples dry from the outside first which leads to shrinkage and then cracking of the grout as the drying continues. This dried and cracked region is highly permeable such that water from the inner regions escapes from the grout by passing through the porous outer region as drying continues. The kinetics of this process are such that a very sharp demarcation boundary exists between the two phases. The results indicate that drying from the surface of grout can lead to irreversible cracking and increased permeability and porosity in the dried region.

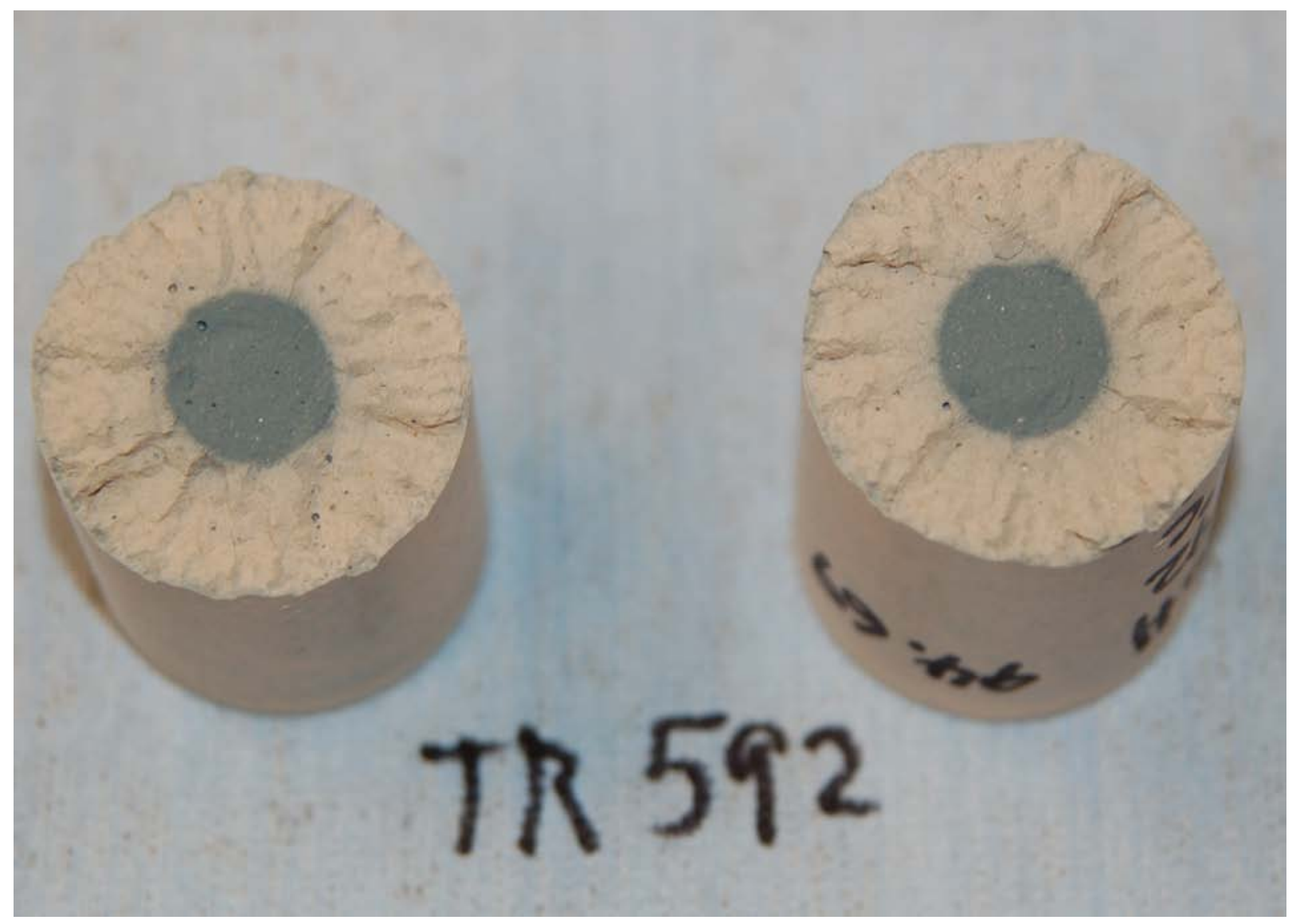

Figure 3-16 A partially dried cured sample (2 inch diameter) from premix and 3.0 M $\mathrm{NaOH}$ at $0.60 \mathrm{w} / \mathrm{cm}$ ratio and cured at $22{ }^{\circ} \mathrm{C}$. This sample was easily broken by hand. 


\subsection{RESULTS AND DISCUSSION FOR PHASE 11}

Phase 11 used an ARP/MCU simulated salt solution containing $0.22 \mathrm{M}$ aluminate for all the mixes and investigated the impact of increasing the wt \% of PC at the expense of FA in the premix. The experimental design is presented in Table 4-1.

Table 4-1 Experimental Design for Phase 11.

\begin{tabular}{|c|c|c|c|c|c|c|c|c|c|c|}
\hline & \multicolumn{8}{|c|}{ Grout Variability Study Phase $11 \mathrm{MCU}$} & \multirow[b]{2}{*}{ Phosphate } & \multirow[b]{2}{*}{ Aluminate } \\
\hline Run Number & Temp & Water/Premix & OPC & FA & Slag & Added OH & Free OH & Nitrate plus Nitrite & & \\
\hline Run Order & ${ }^{\circ} \mathrm{C}$ & Ratio & Wt $\%$ & Wt \% & Wt \% & Molarity & Molarity & Molarity & Molarity & Molarity \\
\hline GVS116 & 22 & 0.56 & 22.5 & 32.5 & 45 & 2.68 & 1.80 & 2.91 & 0.012 & 0.22 \\
\hline GVS117 & 22 & 0.60 & 15 & 40 & 45 & 2.68 & 1.80 & 2.91 & 0.012 & 0.22 \\
\hline GVS118 & 22 & 0.60 & 30 & 25 & 45 & 2.68 & 1.80 & 2.91 & 0.012 & 0.22 \\
\hline GVS119 & 22 & 0.52 & 15 & 40 & 45 & 2.68 & 1.80 & 2.91 & 0.012 & 0.22 \\
\hline GVS120 & 22 & 0.52 & 30 & 25 & 45 & 2.68 & 1.80 & 2.91 & 0.012 & 0.22 \\
\hline
\end{tabular}

\subsection{Impact of Increased Cement Content in the Mix}

A comparison on the impact of an increase in the portland cement wt $\%$ in the premix at the expense of the fly ash on the ARP/MCU mix properties can be made using two mixes that were identical except for the wt \% portland cement concentration (10 wt \% for GVS110 vs. $30 \mathrm{wt} \%$ for GVS118). GVS110 is the baseline mix at $0.60 \mathrm{w} / \mathrm{cm}$ ratio with a salt stream composition projected by Thuy Le.

The fresh and cured grout properties of these two mixes are presented in Table 4-2. The set time is reduced to 1 day at $22{ }^{\circ} \mathrm{C}$ for the higher cement mix consistent with the shorter induction period of 3 hours versus the 48 hours for the GVS110 mix. The gel time is reduced to 5 minutes with $30 \mathrm{wt} \%$ cement and the yield stress and plastic viscosity also increase as a result of increased cement. Although the heat of hydration is greater in GVS118, the values of E are less than the corresponding value with the baseline mix. On the other hand, the porosities for the two mixes are roughly the same. This effect of improved permeability and Young's modulus has been reported in the literature for mixes containing higher ratios of slag to cement [9]. This difference in performance properties for mixes containing a higher proportion of cement leads to difficulty in the predictive models (see Section 6).

Table 4-2 Fresh and Cured Grout Properties for GVS110 and GVS118

\begin{tabular}{|c|c|c|c|c|c|c|c|c|}
\hline \multirow[b]{2}{*}{ Identifier } & & \multirow{2}{*}{$\begin{array}{c}\text { Fresh } \\
\text { Density }\end{array}$} & \multirow{2}{*}{$\begin{array}{c}\text { Cured } \\
\text { Density }\end{array}$} & \multirow[b]{2}{*}{ Flow } & \multirow[b]{2}{*}{ Yield Stress } & \multirow[b]{2}{*}{ Viscosity } & \multirow[b]{2}{*}{ Bleed } & \multirow[b]{2}{*}{ Set Time } \\
\hline & Gel Time & & & & & & & \\
\hline & minutes & $\mathrm{g} / \mathrm{mL}$ & $\mathrm{g} / \mathrm{mL}$ & $\mathrm{cm}$ & $\mathrm{Pa}$ & $c P$ & Vol \% & Days \\
\hline GVS110 & 30 & 1.722 & 1.750 & 23.3 & 4.7 & 89.5 & 0.5 & 3.0 \\
\hline \multirow[t]{3}{*}{ GVS118 } & 5 & 1.761 & 1.796 & 19.7 & 6.9 & 116.1 & 0.0 & 1.0 \\
\hline & Porosity & Heat & $E$ & & & & & \\
\hline & Volume \% & $\mathrm{J} / \mathrm{g} \mathrm{cm}$ & $\mathrm{GPa}$ & & & & & \\
\hline GVS110 & 57.2 & 202.0 & 8.8 & & & & & \\
\hline GVS118 & 56.8 & 239.0 & 7.2 & & & & & \\
\hline
\end{tabular}




\subsection{Phase 11 - E as a Function of w/cm Ratio and Wt \% Cement}

The values of Young's moduli for the five ARP/MCU mixes for Phase 11 as a function of w/cm ratio at two different cement loadings are presented in Table 4-3. The baseline ARP/MCU mix, GVS110, from Phase 10 is also included for reference. The Phase 11 samples were cured under sealed conditions at room temperature $\left(22^{\circ} \mathrm{C}\right)$.

Table 4-3 Young's Modulus Values for the Phase 11 Mixes.

\begin{tabular}{|c|c|c|c|}
\hline \multicolumn{4}{|c|}{ Young's Modulus in GPa after 31 Days } \\
\hline & $22{ }^{\circ} \mathrm{C}$ & $40^{\circ} \mathrm{C}$ & $60^{\circ} \mathrm{C}$ \\
\hline GVS110 & 8.8 & 7.2 & 4.5 \\
\hline GVS116 & 7.7 & 6.6 & 6.4 \\
\hline GVS117 & 8.0 & 5.9 & 4.4 \\
\hline GVS118 & 7.2 & 6.5 & 6.8 \\
\hline GVS119 & 9.0 & 7.0 & 5.9 \\
\hline GVS120 & 8.6 & 8.0 & 8.4 \\
\hline
\end{tabular}

An increase in cement concentration in the premix from $10 \mathrm{wt} \%$ to $15 \mathrm{wt} \%$ to $30 \mathrm{wt} \%$ reduces E for samples cured at $22{ }^{\circ} \mathrm{C}$ for a w/cm ratio of 0.60 (Figure 4-1). Reducing the $\mathrm{w} / \mathrm{cm}$ ratio from 0.60 to 0.52 at $22{ }^{\circ} \mathrm{C}$ increases Young's modulus at the same premix composition. On the other hand, samples with higher cement content that are cured at either $40^{\circ} \mathrm{C}$ or $60^{\circ} \mathrm{C}$ show improvement in $\mathrm{E}$ over the baseline mix at these curing temperatures. In fact, the mixes containing $30 \mathrm{wt} \%$ cement in the premix (GVS118 and GVS120) have E values that are relatively insensitive to the temperature of curing (Table 4-3). The mixes with lower levels of cement show greater reduction in $\mathrm{E}$ at higher curing temperatures, a response that is typical of mixes with the nominal premix composition.

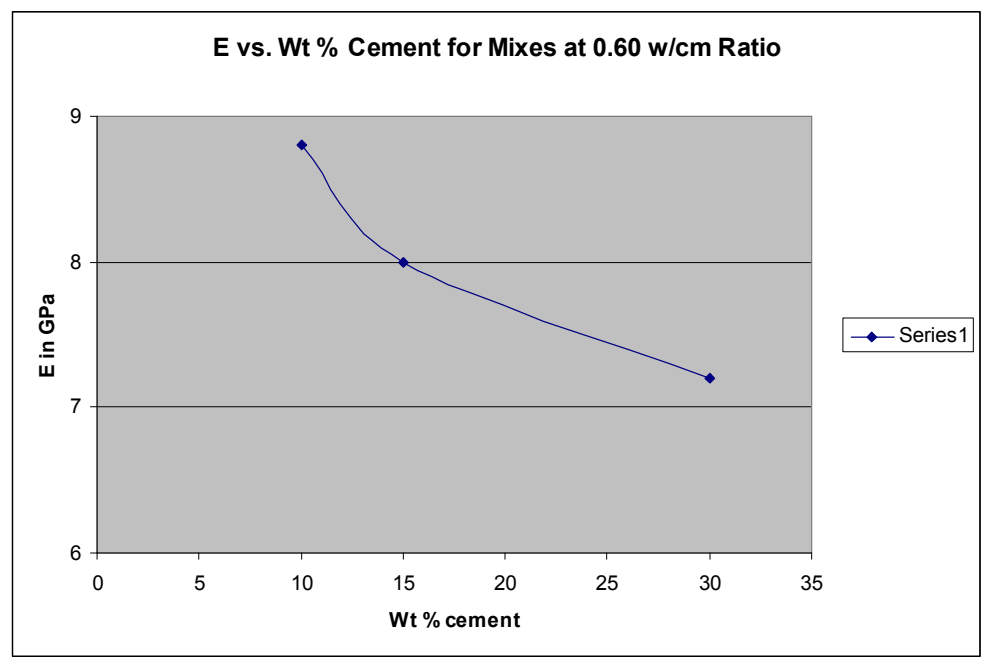

Figure 4-1 E vs. wt \% cement in baseline ARP/MCU mix for samples cured at $22{ }^{\circ} \mathrm{C}$. 
The time dependence of $\mathrm{E}$ for a curing temperature of $22{ }^{\circ} \mathrm{C}$ is given in Figure $4-2$ for each of the 5 mixes of Phase 11 plus GVS110 from Phase 10 (brown-colored curve). Relative to the baseline ARP/MCU mix (GVS110), these samples show a greater increase in E with time out to measurements at 91 days.

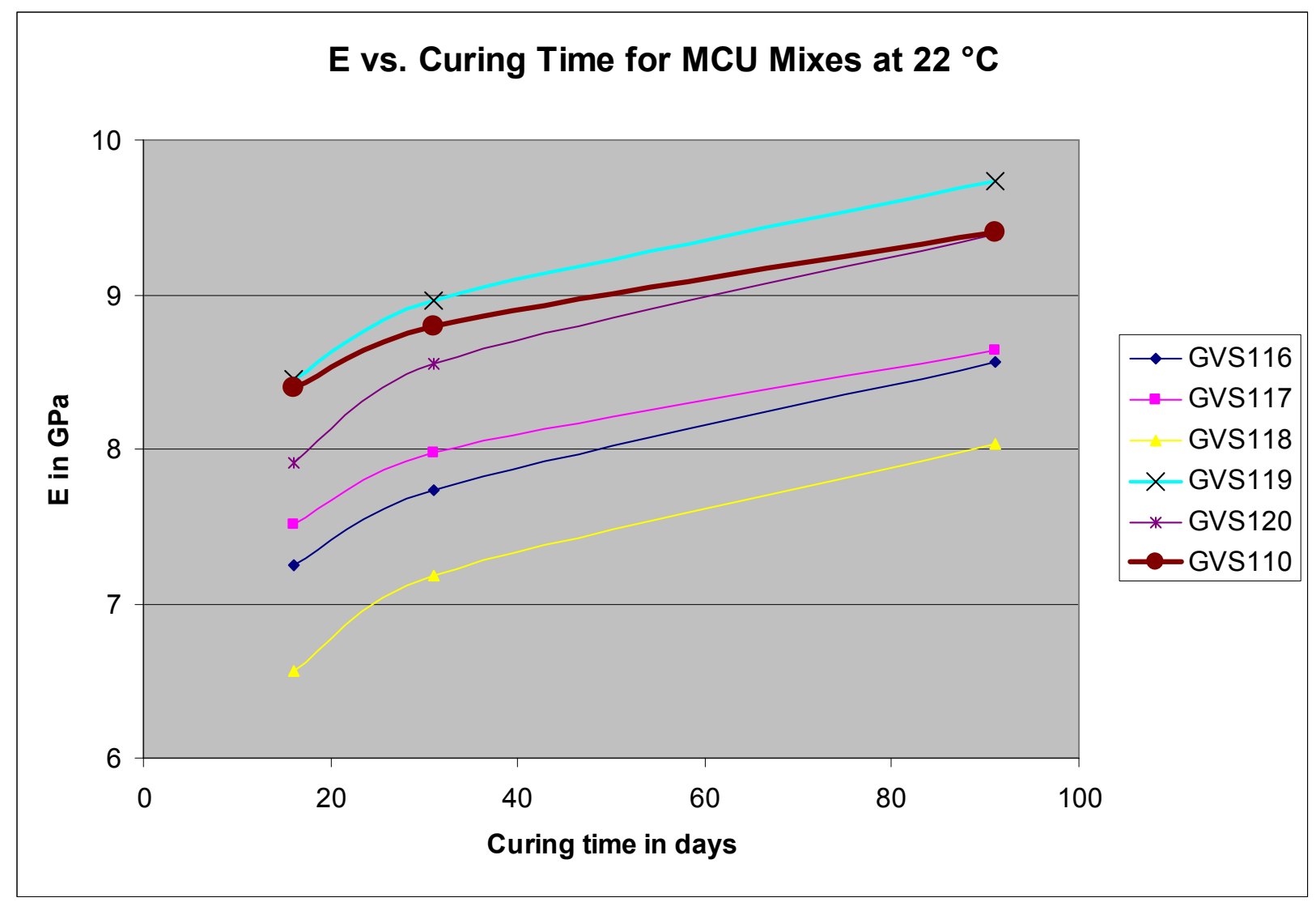

Figure 4-2 Time dependence of $\mathrm{E}$ at $22^{\circ} \mathrm{C}$ curing temperature for the five mixes of Phase 11 plus GVS110 from Phase 10.

\subsection{Young's Modulus at Different Time/Temperature Curing Profiles}

Previous results [4] have shown that the performance properties of the mixes depend on the time/temperature profile for curing. Figure 4-3 shows the dependence of $E$ on time and temperature curing profiles for a mix at $0.60 \mathrm{w} / \mathrm{cm}$ ratio (GVS118) with a cement concentration of $30 \mathrm{wt} \%$ of the premix. The time/temperature curing profile for each curve is provided in the table below the figure. The data show that an increase in temperature to $60{ }^{\circ} \mathrm{C}$ after 1 or 2 days curing at $22{ }^{\circ} \mathrm{C}$ does not significantly reduce $\mathrm{E}$. This is in contrast to the previous results of this report for a mix containing the nominal premix distribution (Section 3-3). For mixes cured initially at $60^{\circ} \mathrm{C}$, removal after 1 or 2 days at $60^{\circ} \mathrm{C}$ followed by curing at $22^{\circ} \mathrm{C}$, results in mixes with lower $\mathrm{E}$ values than the mix cured for 7 days at $60{ }^{\circ} \mathrm{C}$. This pattern is consistent with mixes batched with the nominal premix distribution (Section 3-3). 


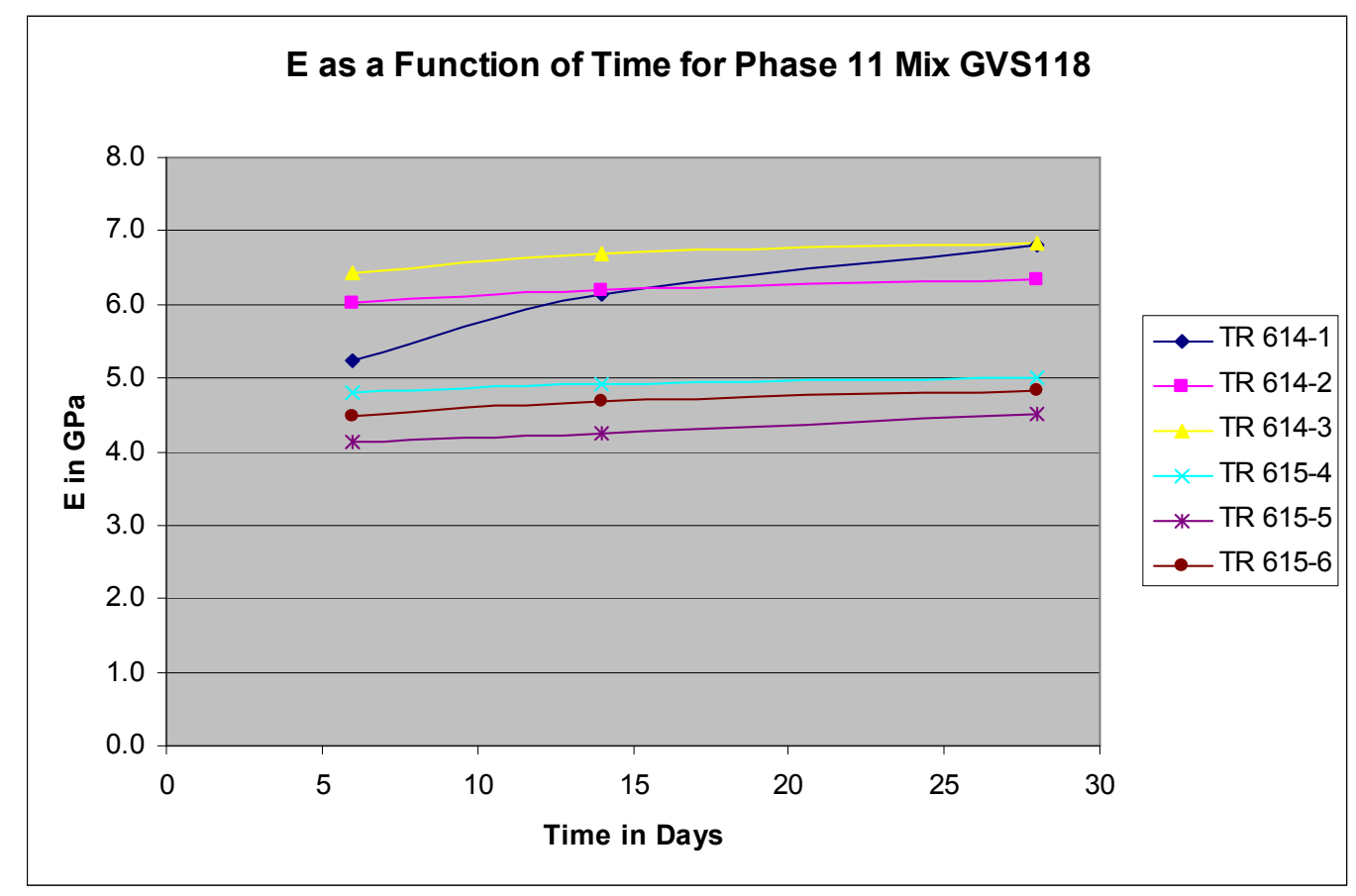

\begin{tabular}{|c|c|l|c|}
\hline TR \# & Time/ Temperature Profile & TR \# & Time/ Temperature Profile \\
\hline TR 614-1 & Curing only at $22{ }^{\circ} \mathrm{C}$ & TR $615-4$ & 7 days at $60{ }^{\circ} \mathrm{C}$ \\
\hline TR 614-2 & 1 day at $22^{\circ} \mathrm{C}$ and 6 days at $60{ }^{\circ} \mathrm{C}$ & TR $615-5$ & 1 day at $60{ }^{\circ} \mathrm{C}$ and 6 days at $2{ }^{\circ} \mathrm{C}$ \\
\hline TR 614-3 & 2 days at $22^{\circ} \mathrm{C}$ and 5 days at $60{ }^{\circ} \mathrm{C}$ & TR $615-6$ & 2 days at $60{ }^{\circ} \mathrm{C}$ and 5 days at $22{ }^{\circ} \mathrm{C}$ \\
\hline
\end{tabular}

Figure 4-3 E as a function of curing time for the profiles given in the legend for GVS118.

\subsection{Porosities as a Function of Curing Temperature and Time}

The total porosity values for the Phase 11 mixes along with the baseline mix (GVS110) are provided in Table 4-4. For samples cured at $22^{\circ} \mathrm{C}, \Phi$ decreases with $\mathrm{w} / \mathrm{cm}$ ratio but is independent of the cement concentration. These porosities are also less than $\Phi$ for the baseline mix. The porosities decrease for samples cured at either $40{ }^{\circ} \mathrm{C}$ or $60{ }^{\circ} \mathrm{C}$ relative to $22{ }^{\circ} \mathrm{C}$ for all of the mixes except those containing $30 \mathrm{wt} \%$ cement. For the high cement mixes, the porosities are essentially independent of the curing temperature and consistent with the trend of Young's moduli which were also independent of curing temperature. 
Table 4-4 Total Porosity Values for the Phase 11 Mixes.

\begin{tabular}{|c|c|c|c|}
\hline \multicolumn{5}{|c|}{ Total Porosity after 31 days } \\
\hline & $22{ }^{\circ} \mathrm{C}$ & $40^{\circ} \mathrm{C}$ & $60{ }^{\circ} \mathrm{C}$ \\
\hline GVS110 & 0.572 & 0.589 & 0.599 \\
\hline GVS116 & 0.552 & 0.567 & 0.580 \\
\hline GVS117 & 0.567 & 0.591 & 0.591 \\
\hline GVS118 & 0.568 & 0.571 & 0.561 \\
\hline GVS119 & 0.538 & 0.559 & 0.561 \\
\hline GVS120 & 0.535 & 0.536 & 0.526 \\
\hline
\end{tabular}

\subsection{Heat of Hydration}

The heat of hydration data for Phase 11 mixes are provided in Table 4-5. As the w/cm ratio increases for both the 15 and $30 \mathrm{wt} \%$ cement mixes, the heat of hydration normalized to the premix content actually increases slightly. As the PC content is increased from 15 to $30 \mathrm{wt} \%$, the normalized heat of hydration also increases. However, a reduction in $\mathrm{w} / \mathrm{cm}$ ratio from 0.60 to 0.52 reduces the $\mathrm{J} / \mathrm{g}$ of premix produced over the same time period. Higher cement content at either $\mathrm{w} / \mathrm{cm}$ ratio shortens the peak time for heat generation. The model produced and discussed in Section 5 of this report details the dependence of heat of hydration on the significant factors for the combination of Phase 10 and 11 mixes.

Table 4-5 Heat of Hydration and Peak Time for Heat Generation for Phase 11 Mixes.

\begin{tabular}{|c|c|c|c|c|}
\hline Identifier & Channel \# & Heat of Hydration & Heat of Hydration & Peak time \\
\hline & & J/g of premix & J/g of grout & hours \\
\hline GVS116 & 1 & 211 & 118 & 6 \\
\hline GVS117 & 2 & 208 & 112 & 11 \\
\hline GVS118 & 3 & 239 & 129 & 3 \\
\hline GVS119 & 4 & 192 & 109 & 22 \\
\hline GVS120 & 5 & 221 & 127 & 4 \\
\hline
\end{tabular}

\subsection{Processing Properties for Phase 11 Mixes}

Task 3 focused mainly on the performance properties of the ARP/MCU Saltstone mixes. However, the processing properties must also be acceptable for processing at SPF. The processing property results for Phase 11 mixes are presented in Table 4-6. Almost all of the mixes had gel times that were less than 20 minutes. Therefore, a set retarder may be required if a premix with higher levels of cement were used at Saltstone. The mixes had relatively high yield stress and plastic viscosity values with the higher cement content. Acceptance criteria for the flow properties have yet to be established and pumping calculations will be required to determine 
these criteria. There was no bleed on any of the samples and the set time was 1 day for all the mixes except GVS117 in spite of the fact that these mixes had relatively high aluminate levels. This suggests that a larger concentration of portland cement in the premix accelerates the set. For these mixes cured at either $40^{\circ} \mathrm{C}$ or $60{ }^{\circ} \mathrm{C}$ there was no bleed water at 1 day.

Table 4-6 Processing Properties for Phase 11 Mixes.

\begin{tabular}{|c|c|c|c|c|c|c|c|c|c|c|c|c|c|}
\hline & & Fresh & Cured & & Uncorrected & \multicolumn{3}{|c|}{ 1-Day Bleed } & & 3-Day Bleed & \multicolumn{3}{|c|}{ Set Time } \\
\hline Identifier & Gel Time & Density & Density & Flow & \begin{tabular}{|l} 
Yield Stress \\
\end{tabular} & Viscosity & $22{ }^{\circ} \mathrm{C}$ & $40^{\circ} \mathrm{C}$ & $60^{\circ} \mathrm{C}$ & $22^{\circ} \mathrm{C}$ & $22^{\circ} \mathrm{C}$ & $40^{\circ} \mathrm{C}$ & $60^{\circ} \mathrm{C}$ \\
\hline & minutes & $\mathrm{g} / \mathrm{mL}$ & $\mathrm{g} / \mathrm{mL}$ & $\mathrm{cm}$ & $\mathrm{Pa}$ & $\mathrm{cP}$ & Vol \% & Vol \% & Vol \% & Vol \% & Days & Days & Days \\
\hline GVS116 & 5 & 1.772 & 1.796 & 20.1 & 10.4 & 139.0 & 0.0 & 0.0 & 0.0 & 0.0 & 1 & 1 & 1 \\
\hline GVS117 & 20 & 1.728 & 1.761 & 23.5 & 4.0 & 76.6 & 0.4 & 0.5 & 0.0 & 0.0 & 2 & 1 & 1 \\
\hline GVS118 & 5 & 1.761 & 1.796 & 19.7 & 6.9 & 116.1 & 0.0 & 0.0 & 0.0 & 0.0 & 1 & 1 & 1 \\
\hline GVS119 & 10 & 1.789 & 1.823 & 20.3 & 7.9 & 141.8 & 0.0 & 0.0 & 0.0 & 0.0 & 1 & 1 & 1 \\
\hline GVS120 & 5 & 1.843 & 1.865 & 17.5 & 15.8 & 206.3 & 0.0 & 0.0 & 0.0 & 0.0 & 1 & 1 & 1 \\
\hline
\end{tabular}

\subsection{Drying Shrinkage and Cracking}

Cast samples of GVS116 through GVS120 were placed in a $40{ }^{\circ} \mathrm{C}$ oven and weighed periodically to determine the rate of water loss from the $2 \times 4$ inch cylinders. The time dependence of this mass loss is shown in Figure 4-4. The loss in wt \% is in expected order with higher water loss observed for those samples having higher $\mathrm{w} / \mathrm{cm}$ ratios and lower water loss for those samples containing higher concentrations of portland cement.

Figure 4-5 shows a plot of mass loss at $40{ }^{\circ} \mathrm{C}$ versus the mass loss at $105{ }^{\circ} \mathrm{C}$ for these five samples. This plot shows that the mass loss at $105^{\circ} \mathrm{C}$ is $\sim 22 \%$ greater than the mass loss at 40 ${ }^{\circ} \mathrm{C}$ for all of the samples. 
Rev. 0

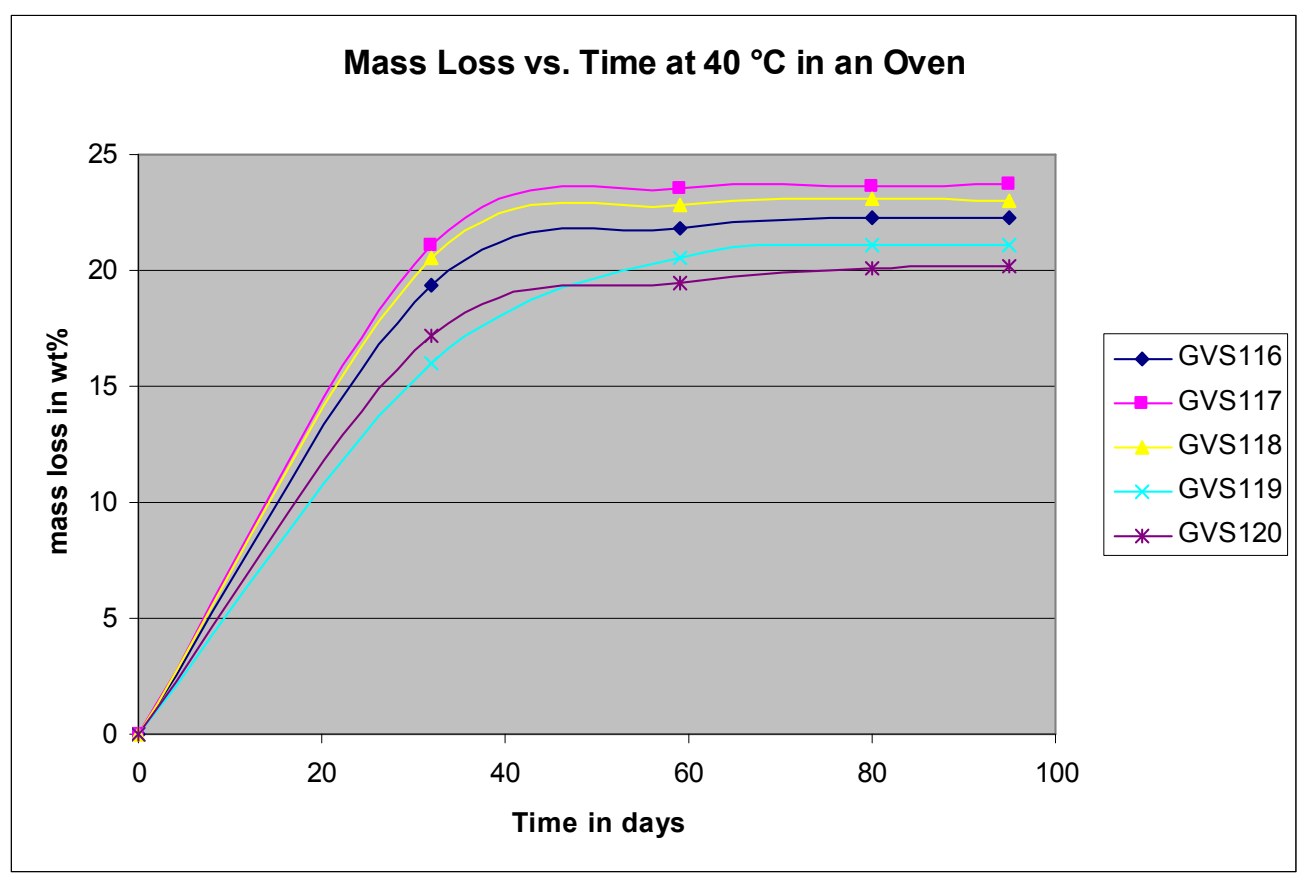

Figure 4-4 Mass loss in wt \% for the 2 x 4 inch cast samples of GVS116 through GVS120.

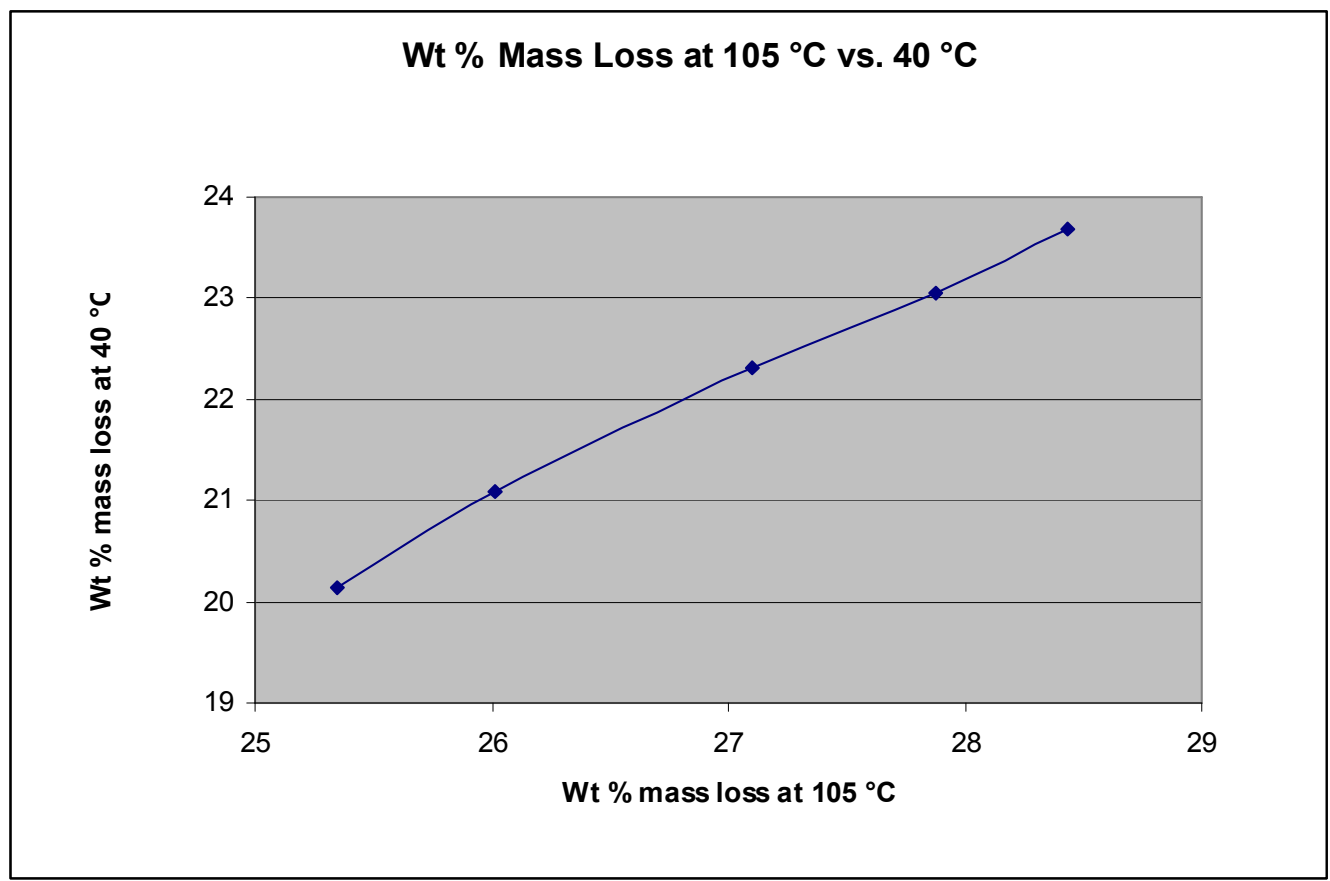

Figure 4-5 A comparison of mass loss in wt \% for drying at $40{ }^{\circ} \mathrm{C}$ vs. $105{ }^{\circ} \mathrm{C}$ for the $2 \times 4$ inch cast samples of GVS116 through GVS120. 
Figure 4-6 provides a photograph of GVS120 after drying and rehydration. Before breakage, surface cracks are evident in this photo (image on the left). An image of the cross section of this cast cylinder after breakage by hand into two pieces is shown on the right side of this figure. The surface consists of jagged edges reflective of cleavage along the cracks. These results were similar to those seen for samples dried and broken from Phase 10 of this task (with high aluminate in the salt feed).

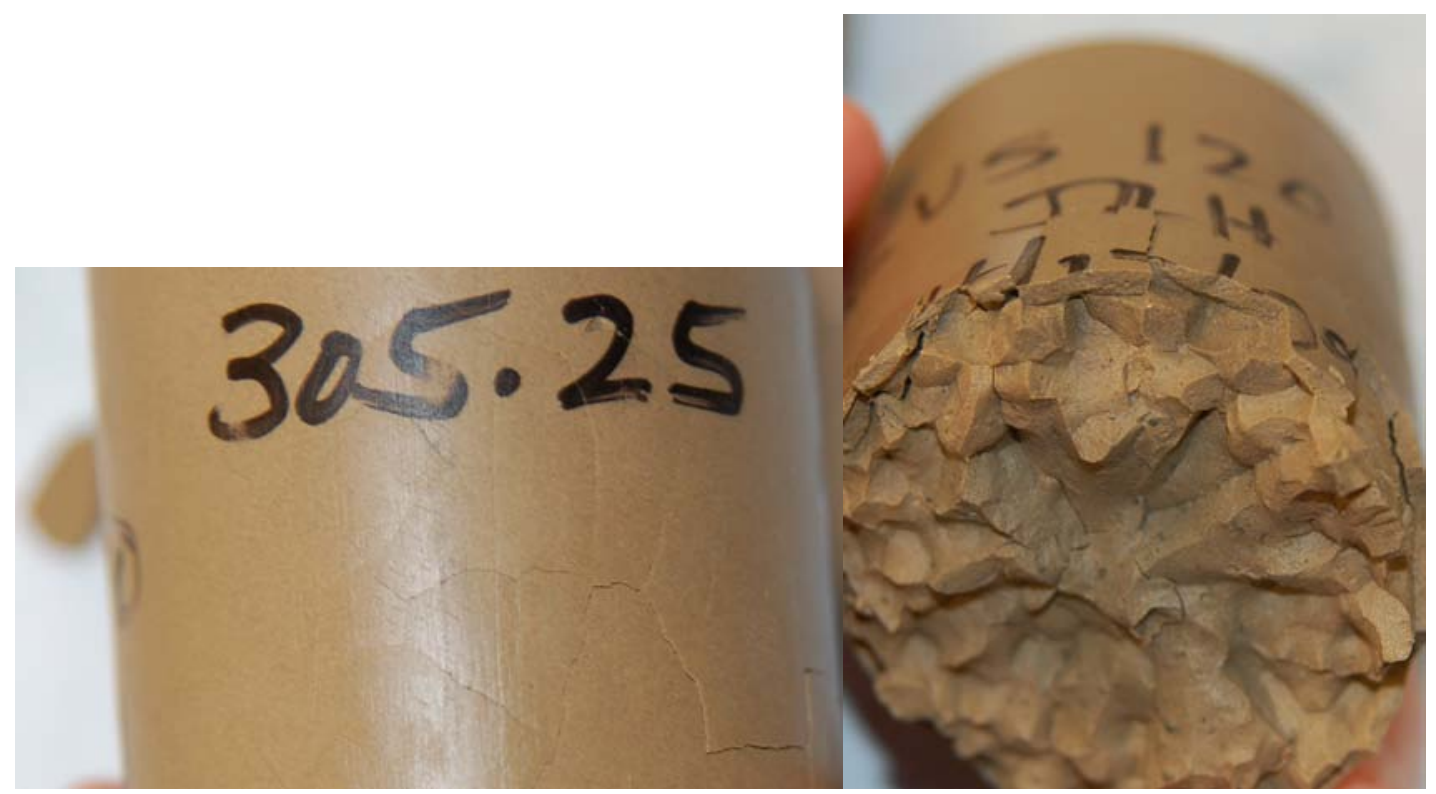

Figure 4-6 Photographs of GVS120 after drying and rehydration (left side) and breakage (right side).

\subsection{CORRELATION OF POROSITY AND YOUNG'S MODULUS}

Figure 5-1 is the plot of Young's modulus (E) versus total porosity $(\Phi)$ for all of the mixes of Phases 10 and 11 cured at $22{ }^{\circ} \mathrm{C}$ [11]. Phase 10 data are designated by gold squares whereas phase 11 samples are designated by purple filled circles. It is clear from this figure that phase makes a difference in the correlation. The offset reflects the incorporation of higher concentrations of cement in the Phase 11 samples. As indicated earlier in this report, the use of slag at the expense of cement in mixes improves permeability and presumably Young's modulus. Since cement was increased at the expense of fly ash, the impact of reduced fly ash concentration in the premix also has to be considered. Fly ash is also known to improve permeability.

Therefore, both the increase in cement and decrease in fly ash concentrations result in a mix with lower E values. One approach to dealing with this property is to correlate only over a similar type of premix. The changes in cement and fly ash in the Phase 11 mixes is larger than would be normally expected for operational variation of these concentrations at the SPF. Therefore, for a given batch, a unique correlation may be determined that is appropriate for the premix composition selected. 


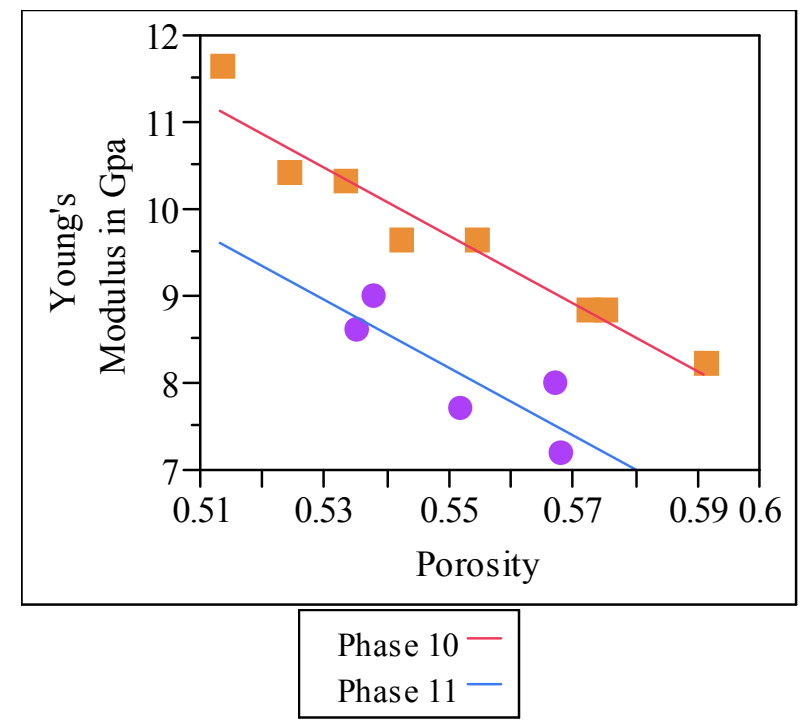

Figure 5-1 Correlation of $E$ and $\Phi$ for Phases 10 and 11 mixes cured at $22{ }^{\circ} \mathrm{C}$. The purple circles are Phase 11 mixes and the gold squares are Phase 10 mixes.

When results of $\mathrm{E}$ and $\Phi$ from all the mixes at all three curing temperatures are plotted, the result shown in Figure 5-2 is obtained with a higher degree of scatter as reflected in an $\mathrm{R}^{2}$ of $67 \%$.

The difference in correlation between the two phases is still evident. The linear correlation based on all of the results is represented by the following equation:

$$
\mathrm{E}(\mathrm{GPa})=38.22757-54.220437 * \Phi
$$

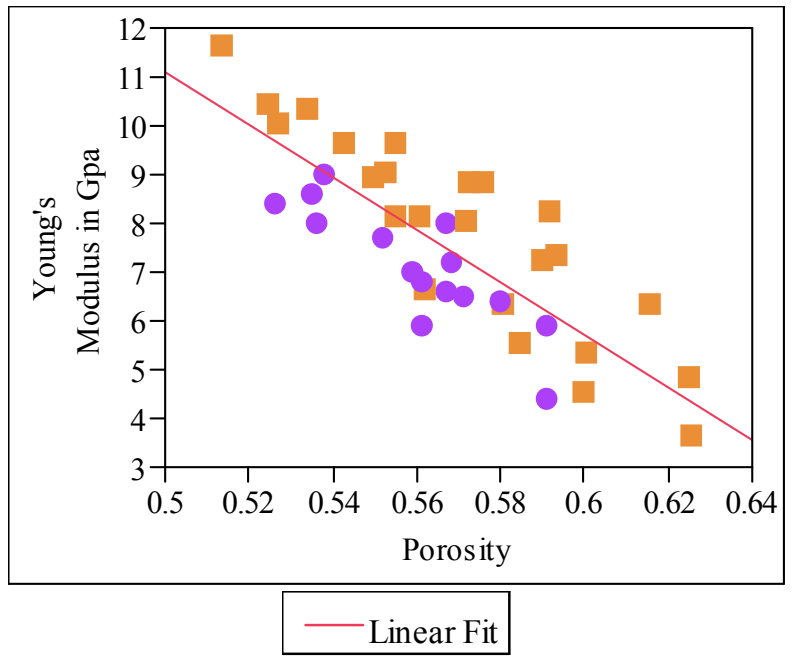

Figure 5-2 Bivariate fit of Young's modulus to total porosity for mixes of Phases 10 and 11 measured at all three curing temperatures. The purple circles are Phase 11 mixes and the gold squares are Phase 10 mixes. 


\subsection{PREDICTIVE MODELING FOR E, Ф AND HEAT OF HYDRATION}

One of the goals of this work was to identify the factors that drive the values of physical properties (responses) of the Saltstone mixes. In this section of the report, the results of models developed using JMP Version 7.02 [11] for Young's modulus, total porosity and heat of hydration are presented. The results using only samples cured at $22{ }^{\circ} \mathrm{C}$ will be presented first and then the results using samples cured at all three temperatures will be presented.

For Young's modulus, the predicted versus actual values are plotted and provide a linear fit with an $\mathrm{R}^{2}$ equal to $95 \%$ (Figure 6-1). These data points are for Phases 10 and 11 for the mixes cured at $22^{\circ} \mathrm{C}$.

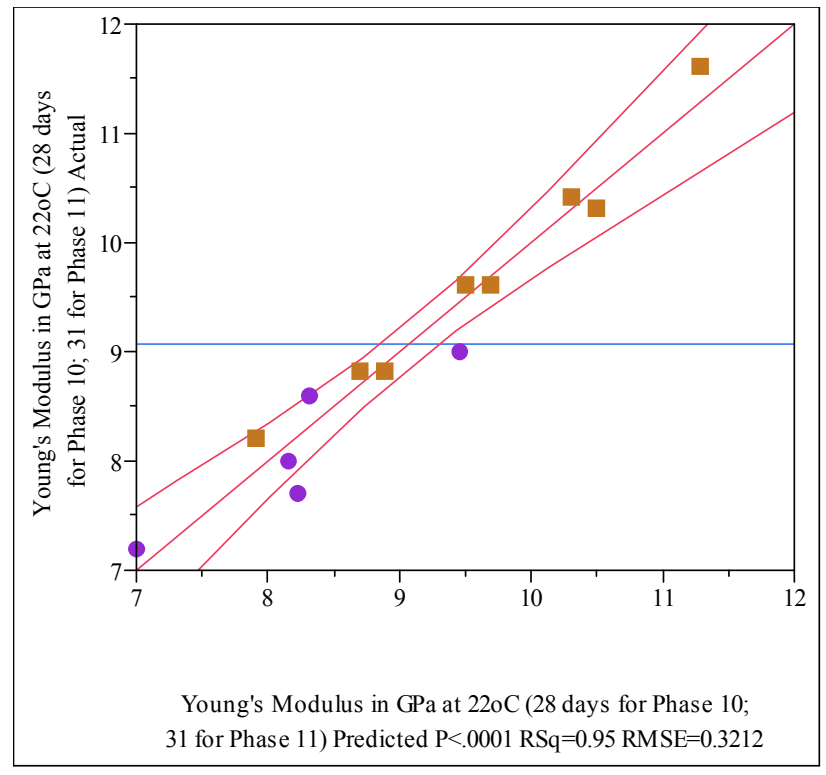

Figure 6-1 Actual versus predicted values of Young's modulus for samples of Phases 10 and 11 for samples cured at $22^{\circ} \mathrm{C}$.

The model (equation) for prediction of $\mathrm{E}$ is:

$\mathrm{E}=16.1-16.3 \cdot \mathrm{w} / \mathrm{cm}+0.07 \bullet \mathrm{wt} \% \mathrm{slag}-0.08 \bullet \mathrm{wt} \%$ cement

For total porosity, the predicted versus actual values are plotted and provide a linear fit with an $\mathrm{R}^{2}$ equal to $99 \%$ (Figure 6-2). These data points are for Phases 10 and 11 for the mixes cured at $22{ }^{\circ} \mathrm{C}$. 


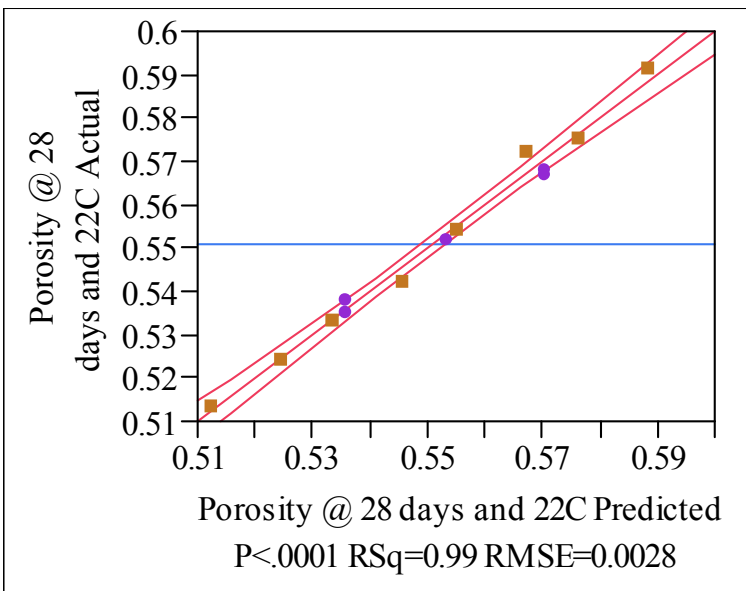

Figure 6-2 Actual vs. predicted values of total porosity for samples of Phases 10 and 11 for samples cured at $22^{\circ} \mathrm{C}$.

The model (with an $\mathrm{R}^{2}$ of $99 \%$ ) for prediction of total porosity $(\Phi)$ expressed as a fraction is:

$\Phi=0.35+0.44 \bullet \mathrm{w} / \mathrm{cm}-0.001 \bullet \mathrm{wt} \% \mathrm{slag}$

The heat of hydration in $\mathrm{J} / \mathrm{g}$ of $\mathrm{cm}$ was also modeled and the results are provided in Figure 6-3.

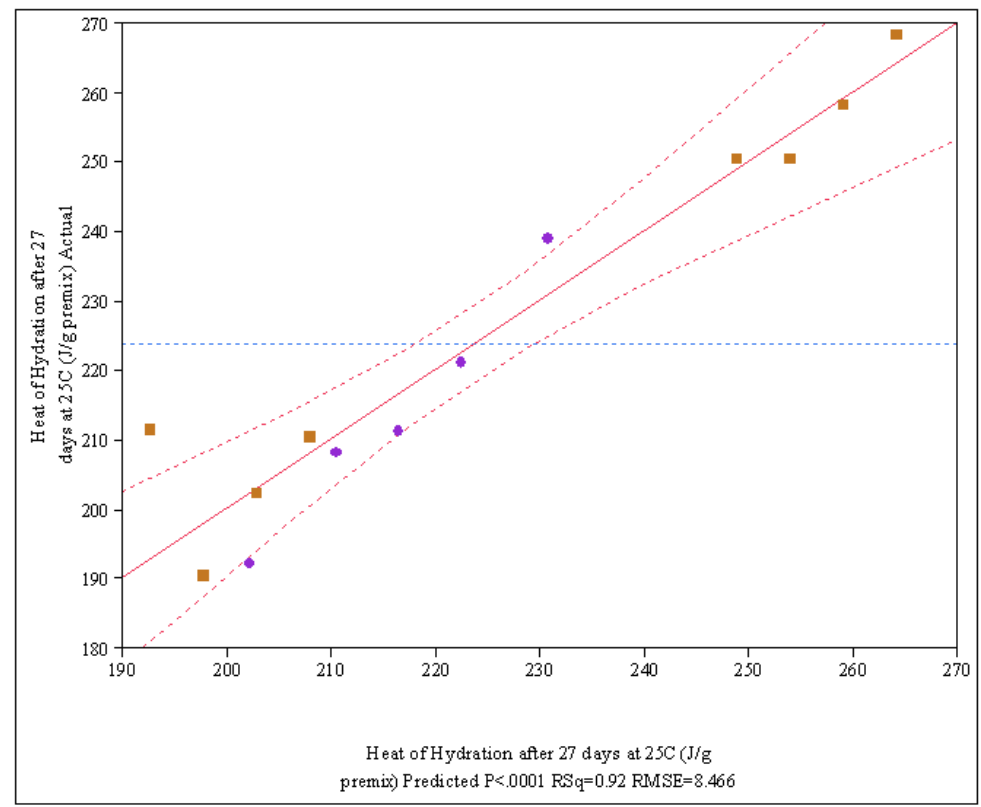

Figure 6-3 Actual vs. predicted values of heat of hydration for samples of Phases 10 and 11 for samples cured $25^{\circ} \mathrm{C}$ only. 
The model (equation) for prediction of heat of hydration $(\mathrm{HOH})$ expressed in $\mathrm{J} / \mathrm{g}$ of $\mathrm{cm}$ is:

$\mathrm{HOH}=94.2+104.4 \bullet \mathrm{w} / \mathrm{cm}+2.4 \bullet \mathrm{wt} \%$ slag $-1.4 \bullet \mathrm{wt} \% \mathrm{FA}$

The $\mathrm{R}^{2}$ for this fit is $92 \%$ and identifies $\mathrm{w} / \mathrm{cm}$ ratio, wt $\%$ slag and $\mathrm{wt} \% \mathrm{FA}$ as the significant drivers of the heat of hydration of the Saltstone mixes.

The predicted versus actual values for Young's modulus for Phases 10 and 11 mixes cured at three different temperatures are plotted in Figure 6-4.

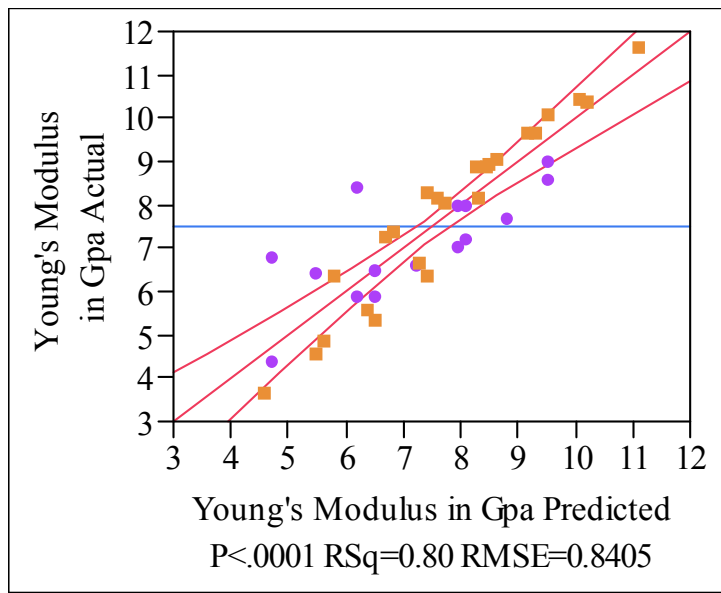

Figure 6-4 Actual versus predicted values of Young's modulus for samples of Phases 10 and 11 for samples cured at all three temperatures.

The model (with an $\mathrm{R}^{2}$ of $80 \%$ ) for prediction of $\mathrm{E}$, where $\mathrm{T}$ is the temperature in ${ }^{\circ} \mathrm{C}$, is:

$\mathrm{E}=17.9-18.3 \cdot \mathrm{w} / \mathrm{cm}+0.07 \cdot \mathrm{wt} \% \mathrm{slag}-0.09 \bullet \mathrm{T}$

The predicted versus actual values for total porosity for Phases 10 and 11 mixes cured at three different temperatures are plotted in Figure 6-5.

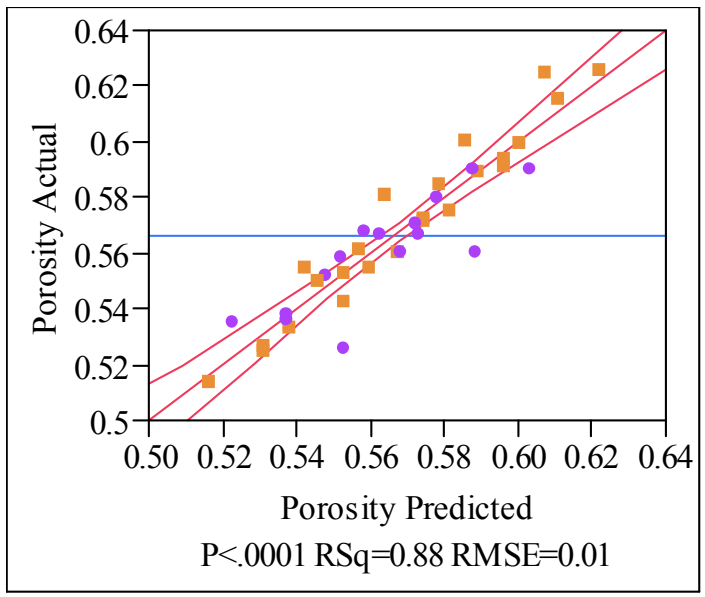

Figure 6-5 Actual vs. predicted values of total porosity for samples of Phases 10 and 11 for samples cured at all three temperatures. 
The model (with an $\mathrm{R}^{2}$ of $88 \%$ ) for prediction of $\Phi$, where $\mathrm{T}$ is the temperature in ${ }^{\circ} \mathrm{C}$, is:

$\Phi=0.25+0.44 \cdot \mathrm{w} / \mathrm{cm}+0.001 \bullet \mathrm{wt} \% \mathrm{FA}+0.0008 \bullet \mathrm{T}$

There are two mixes that have porosities and $\mathrm{E}$ values that are not well predicted by the models. These are the mixes containing $30 \mathrm{wt} \%$ cement cured at $60{ }^{\circ} \mathrm{C}$ (GVS118 and GVS120). As discussed previously, this additional cement concentration does not follow the normal reduction in $\mathrm{E}$ and increase in $\Phi$ that are normally seen as the curing temperature is raised. Therefore, the system is no longer typical of the normal or close to normal premix composition currently used at SPF. Excluding these extreme premix compositions from the model will increase $\mathrm{R}^{2}$ and provide a better predictive equation.

A similar lack of predictability is seen with a difference in the aluminate concentration in the salt solution. GVS107 results were not included in the modeling since it had an aluminate concentration that was very low compared to the projections ( 0.05 vs. $0.22 \mathrm{M})$. Nevertheless this $0.05 \mathrm{M}$ aluminate mix does provide a reference point for understanding the impact of aluminate. With aluminate at this level, $\mathrm{E}$ is much lower and $\Phi$ is much higher than predicted by the models presented in this report. Therefore, the compositional region of the salt solution over which variation is introduced to develop models is extremely important for development of quality models. 


\subsection{CONCLUSIONS}

Task 3 of the FY09 Variability Study focused on the performance (but also measured the processing) properties of Saltstone mixes batched using the projected ARP/MCU decontaminated salt solutions (an average of Batches ISDP3-5). The major conclusions of this task are:

- The relatively high $0.22 \mathrm{M}$ aluminate concentration in the projected ARP/MCU batches significantly increased Young's modulus compared to the previous baseline ARP/MCU composition with $0.05 \mathrm{M}$ aluminate for curing at $22{ }^{\circ} \mathrm{C}$ (E more than doubled from 4.2 to $8.8 \mathrm{GPa})$.

- The total porosity decreased from $59.1 \%$ to $57.2 \%$ from the $0.05 \mathrm{M}$ to the $0.22 \mathrm{M}$ aluminate mixes. Both the increase in $\mathrm{E}$ and reduction in $\Phi$ lead to improved performance for samples cured at $22{ }^{\circ} \mathrm{C}$.

- For the baseline ARP/MCU mix with $0.22 \mathrm{M}$ aluminate and cured at $22^{\circ} \mathrm{C}$, a decrease in the $\mathrm{w} / \mathrm{cm}$ ratio increased $\mathrm{E}$ and reduced $\Phi$. For the nominal premix composition the results were an increase in $\mathrm{E}$ from 8.2 to $10.4 \mathrm{GPa}$ as $\mathrm{w} / \mathrm{cm}$ ratio decreased from 0.65 to 0.50 . $\Phi$ decreased from $59.1 \%$ to $52.4 \%$ over this same range of $\mathrm{w} / \mathrm{cm}$ ratio.

- For the baseline ARP/MCU mix with $0.22 \mathrm{M}$ aluminate and cured at $22{ }^{\circ} \mathrm{C}$, an increase in the slag content (at the expense of fly ash) in the premix from 45 to $60 \mathrm{wt} \% \mathrm{wt} \%$ increased $E$ and reduced $\Phi$. E increased $\sim 8 \%$ while $\Phi$ decreased $\sim 2-3 \%$ for a slag increase from 45 to $60 \mathrm{wt} \%$. Therefore, an increase in slag concentration in the premix improves performance properties.

- For the baseline ARP/MCU mix with $0.22 \mathrm{M}$ aluminate and cured at $22{ }^{\circ} \mathrm{C}$, an increase in the cement content in the premix from 10 to $30 \mathrm{wt} \%$ decreased $\mathrm{E}$ from 8.8 to $7.2 \mathrm{GPa}$. This is opposite of the effect of increased slag concentration in the premix.

- For the baseline ARP/MCU mix with $0.22 \mathrm{M}$ aluminate and cured at $22{ }^{\circ} \mathrm{C}$, a decrease in the $\mathrm{w} / \mathrm{cm}$ ratio for either the 15 or $30 \mathrm{wt} \%$ cement mixes increased $\mathrm{E}$ and decreased $\Phi$.

- Increasing the temperature of curing for the Phase 10 mixes generally decreased $\mathrm{E}$ and increased $\Phi$. However, increasing the temperature of curing for the mixes of Phase 11 with higher cement concentrations revealed that $\mathrm{E}$ and $\Phi$ were not as sensitive to (i.e., did not decrease in value) the temperature of curing as compared to mixes using the normal premix.

- The sequence of time and temperature of curing again played a major role in the final performance properties of the phase 10 mixes. This effect was mitigated for the Phase 11 mixes containing higher cement levels.

- For the Phase 10 mixes, the processing properties were generally acceptable except for those mixes at low w/cm ratios. The measured gel times for these mixes were 10 minutes and the viscosities and yield strengths were higher than normal. Similar results were found for the Phase 11 mixes where high levels of cement produced short gel times.

- Drying tests were performed for all of the mixes from Phases 10 and 11 at $40{ }^{\circ} \mathrm{C}$. Over the period of one to two months, the mass loss due to water evaporation approached 20 wt $\%$. 
- The dried samples when broken apart revealed smaller pieces with surfaces consisting of jagged edges reflective of cleavage along the cracks. This behavior was observed with samples containing $0.22 \mathrm{M}$ aluminate. For the $0.05 \mathrm{M}$ aluminate mix, this behavior was not observed and the cylinder broke apart into several large pieces with relatively smooth surfaces. The preliminary conclusion is that aluminate produces a microstructure that is susceptible to cracking.

- Partially dried samples (<10 wt \% loss), when broken apart revealed distinct cross sectional regions. The outer region was highly fractured whereas the inner region was blue in color, saturated and intact.

- The mechanism leading to this observation is drying shrinkage and subsequent cracking. Evidently the samples dry from the outside first which leads to shrinkage and then cracking of the grout as the drying continues. This dried and cracked region is highly permeable such that water from the inner regions escapes from the grout by passing through the porous outer region. The kinetics of this process are such that a very sharp demarcation boundary exists between the two phases.

- Correlations of $\mathrm{E}$ with $\Phi$ reveal that Phase 10 mixes produce a curve which is parallel but offset from the curve for Phase 11 mixes. This is due to the fact that cement and slag produce mixes with different values of $E$ and $\Phi$ for the same degree of hydration. Slag in general produces a grout with higher $\mathrm{E}$, lower $\Phi$, and lower permeability.

- Linear models were developed relating performance properties to the experimental factors for the mixes cured at $22{ }^{\circ} \mathrm{C}$. The models have high $\mathrm{R}^{2}$ values and identify the key factors that drive the values of $\mathrm{E}, \Phi$ and heat of hydration. However, the same predictive models produce more scatter when the results for samples cured at all temperatures are included. The outliers in these plots are the mixes with $30 \mathrm{wt} \%$ cement cured at $60{ }^{\circ} \mathrm{C}$ which as described above reflects differences in response between cement and slag. The next generation of models may exclude these mixes with high values of cement since they may not be applicable to processing at SPF. 


\subsection{PATH FORWARD}

The results in this report indicate that in order to meaningfully measure the performance properties of Saltstone, one has to know the time/temperature profile conditions under which the Saltstone will be cured. This will require thermal modeling and/or actual time/temperature profiles within the vaults under various pour schedules to determine (1) an average profile of time and temperature under normal processing and (2) a conservative (worst case) profile. Samples can then be cast and cured in the laboratory under these time and temperature profiles prior to measurement of the performance properties of the product waste forms.

This study reveals that drying of the Saltstone, even at relatively low temperatures (e.g., 40 C) can result in shrinkage and subsequent irreversible cracking. It is recommended that the factors that drive this shrinkage be identified and a strategy proposed to mitigate this process.

The role of aluminate and curing temperature as significant drivers of the performance properties suggests that these factors bring about microstructural changes. It is therefore suggested that the microstructure of these samples be investigated by scanning electron microscopy in order to better understand the changes that occur (and consequently, provide a basis for mitigation strategies) as a function of (1) aluminate concentration in the salt solution and (2) curing temperature.

\subsection{REFERENCES}

[1] Memo Report on the Subtasks for the Saltstone Variability Study for 2009, J. R. Harbour and T. B. Edwards, SRNL L3100-2008-00048, October 2008.

[2] Future ISDP Batches to Saltstone Processing Facility, Projected Batch and Key Components Compositions, T. A. Le, LWO-LWP-2009-00005, Rev. 1, 2009.

[3] Effect of Increased Aluminate Concentrations on Saltstone Mixes, J. R. Harbour, T. B. Edwards, E. K. Hansen and V. J. Williams, WSRC-STI-2007-00506, Rev. 0, 2007.

[4] Impact of Time/Temperature Curing Conditions and Aluminate Concentration on Saltstone Properties, J. R. Harbour, T. B. Edwards and V. J. Williams, SRNL-STI-2009-00184, Rev. 0, 2009.

[5] Heat of Hydration of Saltstone Mixes - Measurement by Isothermal Calorimetry, J. R. Harbour, V. J. Williams and T. B. Edwards, WSRC-STI-2007-00263, Rev. 0, 2007.

[6] Saltstone Performance Indicator, J. R. Harbour and V. J. Williams, SRNL-STI-200800488, Rev. 0, December 2008.

[7] Saltstone Variability Study-Measurement of Porosity, J.R. Harbour, V.J. Williams, T.B. Edwards, R.E. Eibling, and R.F. Schumacher, WSRC-STI-2007-00352, Rev. 0. 
[8] Variability Study for Saltstone, J. R. Harbour, T. B. Edwards, E. K. Hansen and V. J. Williams, WSRC-TR-2005-00447, October 2005.

[9] Cement Chemistry, H. F. W. Taylor, Thomas Telford Publishing, 1997.

[10] Permeability of Saltstone, J. R. Harbour, T. B. Edwards, V. J. Williams, D. M. Feliciano and G. W. Scherer WSRC-STI-2007-00437, Rev. 0, 2007.

[11] JMP Version 7.0.2, SAS Institute, Inc. Cary, NC, 1989-2007 